\title{
The effects of nurturing pressure and unemployment on carbon emissions: cross-country evidence
}

\author{
Yu-Qi Liu ${ }^{1}$ Chao Feng ${ }^{1}$ (D)
}

Received: 2 November 2021 / Accepted: 25 February 2022 / Published online: 7 March 2022

(c) The Author(s), under exclusive licence to Springer-Verlag GmbH Germany, part of Springer Nature 2022

\begin{abstract}
Nurturing pressure and unemployment affect our production and life in many ways. The aim of this study is to examine the potential effects of nurturing pressure and unemployment on global $\mathrm{CO}_{2}$ emissions, by using the panel data of 77 countries and regions from 1991 to 2020 and a STIRPAT-based theoretical framework. The results show that at the global level, both nurturing pressure and unemployment overall have negative effects on $\mathrm{CO}_{2}$ emissions. While at the regional level, it becomes a different situation. An increase in nurturing pressure leads to an increase in $\mathrm{CO}_{2}$ emissions in the Americas and the Middle East and a decrease in $\mathrm{CO}_{2}$ emissions in Africa, Europe, and Asia-Pacific. Unemployment has a positive effect on $\mathrm{CO}_{2}$ emissions in the Middle East and a negative effect on $\mathrm{CO}_{2}$ emissions in Africa, Americas, Europe, and the Asia-Pacific regions. There is no evidence that unemployment has certain effects on $\mathrm{CO}_{2}$ emissions in the Middle East and the Asia-Pacific regions.
\end{abstract}

Keywords $\mathrm{CO}_{2}$ emissions $\cdot \mathrm{STIRPAT}$ model $\cdot$ Global $\cdot$ Nurturing pressure $\cdot$ Unemployment

\section{Introduction}

Climate change, mainly characterized by global warming due to the continuous increase of $\mathrm{CO}_{2}$ emissions, has attracted widespread attention worldwide (Anser et al. 2021; Li et al. 2021; Yang et al. 2021). Global warming not only leads to the imbalance of the climate system, but also causes sea-level rise and the reduction of species diversity, which have great impact on the survival and development of human beings. According to the $\mathrm{BP}(2021)$, global $\mathrm{CO}_{2}$ emissions have reached as high as 31,983.6 million tons in 2020 and have maintained an average annual growth rate of $1.4 \%$ in the past decade. This impact usually remains in the atmosphere and oceans for many centuries and poses a huge threat to human survival and economic loss. In the era of globalization, no country can be left alone with the diverse connections between different countries and regions. Therefore, it

Responsible Editor: Ilhan Ozturk

Chao Feng

littlefc@126.com

Yu-Qi Liu

snqzpp@163.com

1 School of Economics and Business Administration, Chongqing University, Chongqing 400030, China has become imperative to take effective measures to reduce carbon emissions on a global scale (Wang et al. 2019; Xu et al. 2021). Studying the drivers of global and regional carbon emissions is not only beneficial for exploring ways to reduce carbon emissions and improve the ecological environment, but also for long-term and short-term environmental policy arrangements of national governments.

Relevant studies have shown with $95 \%$ certainty that human activities are the main cause of $\mathrm{CO}_{2}$ emissions (Pachauri et al. 2014). For decades, scholars have studied the mechanisms by which human activities act on the environment using various methods. Some recent studies confirm that agriculture, tourism, innovations in economic and financial sectors, and related policy implementation may have some impact on carbon emissions at a single national or regional level (Rahman et al. 2021; Chishti et al. 2020; Chishti and Sinha 2022; Chishti et al 2021a, b). Considering the complex mechanisms of human-environment interactions, we argue that the possible impact of two important issues related to human problems, namely, nurturing pressure and unemployment, on carbon emissions cannot be ignored as well, and the policy implications behind them have implications for global low-carbon and sustainable development.

In terms of nurturing pressure, on the one hand, population aging is considered to be a universal phenomenon 
worldwide (Wang and Wang 2021; Jayantha et al. 2018; Li et al. 2019a, b). The latest data from the United Nations indicate that the average annual growth rate of the global aging population from 1990 to 2020 is $2.5 \%$. Its impact on $\mathrm{CO}_{2}$ emissions has gradually attracted the attention of scholars in recent years, and no consistent conclusion has been reached yet. On the other hand, the declining trend of birth rates in many countries and regions also has an impact on the proportion of young people to be dependent, and how it acts on $\mathrm{CO}_{2}$ emissions undoubtedly also deserves attention. Therefore, the impact of nurturing pressure or age structure on $\mathrm{CO}_{2}$ emissions should be considered in both directions, but current studies tend to focus only on the aging of the population, leaving room for further investigation.

In addition, the demographic crisis caused by the irrational development of age structure often coexists with the problem of unemployment, which is another potential influence on $\mathrm{CO}_{2}$ emissions that is more easily neglected. Adesina and Mwamba (2019) focused on the African region and for the first time used the unemployment as one of the influencing factors of $\mathrm{CO}_{2}$ emissions. There are also some studies that demonstrate the inverse relationship between unemployment and environmental pollution (Kashem and Rahman 2020), but further exploration is lacking. In this context, an in-depth understanding of the impact of global and regional unemployment on $\mathrm{CO}_{2}$ emissions is necessary for the effective formulation of relevant policies.

Against this background, the main objective of this paper is to explore whether, to what extent and in what direction nurturing pressure and unemployment affect $\mathrm{CO}_{2}$ emissions at the global and regional scales and what policy directions are implied. Compared with other literatures, the potential contributions and innovations of this paper are as follows: firstly, it extends the traditional analytical framework by adding the non-traditional factors nurturing pressure and unemployment and provides a global perspective and an analysis from each regional perspective, giving the specific degree and direction of influence of the two key factors explored in this paper on $\mathrm{CO}_{2}$ emissions, as well as the corresponding policy recommendations for carbon emission reduction. Secondly, it attaches importance to the selection and comparison of parameter estimation methods, to the data characteristics, and to the comprehensive analysis based on the consideration of the existence of multiple parameter estimation methods with different advantages, rather than relying only on a single estimation method.

This paper is organized as follows: the second section reviews the relevant research literature; the third section introduces the relevant theoretical hypotheses; the fourth section presents the methodology and data sources; the fifth section gives an empirical study of the factors influencing
$\mathrm{CO}_{2}$ emissions at the global and regional levels; and the sixth section gives conclusions and recommendations.

\section{Literature review}

\section{Research on the factors influencing non-traditional carbon emissions}

At present, the study of $\mathrm{CO}_{2}$ emission drivers has become a hot topic of attention among scholars. In addition to population size, GDP per capita, energy intensity, industry share, urbanization level, and other carbon emission influencing factors that have been widely concerned, more and more scholars have also started to focus on non-traditional carbon emission influencing factors in recent years.

The non-traditional factors that the current literatures focus on can be divided into three main categories. The first type of literature focuses on social development facilitators. This includes education level, R\&D level, innovation, etc. The study of Meng et al. (2018) shows that in China, the increase of R\&D intensity is beneficial to promote carbon emission reduction. Mensah et al. (2018) suggest that increasing R\&D intensity can better encourage innovation and thus promote carbon emission reduction in OECD countries. The second group of literature focuses on economic trade-related factors. This includes trade openness, import and export levels, foreign direct investment, etc. Specifically, trade openness has been shown to have a positive impact on $\mathrm{CO}_{2}$ emissions in China, Japan, and South Korea, as well as in countries along the "Belt and Road," but increased cooperation through trade agreements may help to reduce carbon pressure (Dou et al. 2021; Chen et al. 2021). While the reduction of exports will benefit $\mathrm{CO}_{2}$ emission reduction in Turkey in the long run, FDI has been shown to have a nonlinear and time-varying effect on carbon emissions in different countries (Haug and Ucal 2019; Zhou et al. 2018). The third group of literature focuses on population-related factors. These include population density, household size, gender structure, age structure, unemployment rate, etc. For example, Wen and Zhang (2020) insist that population density and household size have positive and negative effects on $\mathrm{CO}_{2}$ emissions in the Beijing-Tianjin-Hebei region of China, respectively. An increase in the proportion of males can promote economic development in some regions of China, which can lead to an increase in carbon emissions ( $\mathrm{Li}$ et al. 2019a, b).

It is worth mentioning that there is a controversy among scholars about the impact of population aging or age structure on carbon emissions. Zhang and Tan (2016) based on data from a provincial panel in China found that population aging has a positive effect on carbon emissions at the 
national level and an uncertain effect at the regional level. The study by Kim et al. (2020) suggests that the fact of population aging reduces $\mathrm{CO}_{2}$ emissions. As for the effect of unemployment on carbon emissions, related studies are very limited. Some scholars have suggested that there is no threshold effect between unemployment and carbon emissions in developed and developing countries but only a linear relationship (Wang and Li 2021), but further exploration at the regional level is lacking. Therefore, there is relatively little literature on the possible effects of nurturing pressure and unemployment on carbon emissions, the findings are unclear, and there are certain research gaps. In addition, youth population change is also an important component of age structure change, but few scholars have considered this factor when focusing on population age structure. Therefore, this paper attempts to further expand the relevant studies from these two aspects.

\section{Research scope of the current literature}

In terms of research scope, there are three broad categories of research scope in the current literature on the drivers of carbon emissions. One is to focus on a specific country and region. Meng et al. (2018) conducted an exponential decomposition of data for 22 Chinese provinces from 2005 to 2014 and found that R\&D efficiency and energy intensity were the main factors inhibiting the growth of carbon emissions, and GDP and investment intensity were the main factors driving the growth of carbon emissions. Chong et al. (2019) studied the factors influencing carbon emissions in Malaysia from 1978 to 2014 and found that in addition to population, GDP per capita, and energy intensity, the role of technology drivers is also increasingly noteworthy. Wang et al. (2020) combined LMDI approach and scenario analysis to study that the key drivers of emission reduction in the USA are the scale effect and technology effect, and the structural effect is less influential. Wang et al. (2019) identify the key drivers of carbon emissions change in the United States and further explore how to decouple economic growth and carbon emissions.

The second is to study the drivers of carbon emissions in geography or regional countries with strong linkages in economic activities. Guo et al. (2020) analyzed the impact of China, Russia, and South Korea on Mongolia's carbon emissions through international trade from a system implementation perspective. Timilsina and Shrestha (2009) explored the drivers of carbon emissions in the transport sector of major Asian countries from 1980 to 2005 and found that changes in GDP per capita, population growth, and changes in energy intensity of transport were the main influencing factors. Dong et al. (2010) focused on China and Japan, two countries with strong trade ties and explored the drivers of
$\mathrm{CO}_{2}$ emissions implicit in their trade from 1990 to 2000 and confirmed the offsetting effect of the sharp decline in carbon intensity of the Chinese economy on the carbon emissions of Chinese exports of Japanese goods. In addition, the environmental pollution transfer from the implied carbon flows accompanying inter-regional trade has increasingly attracted the attention of scholars (Wang et al. 2019; Wang et al. 2020).

Third, the drivers of carbon emissions are explored from a global perspective. Jiang et al. (2021) explored the possible effects of changes in internal and external input structures on global carbon emissions using structural decomposition analysis and found that different drivers of carbon emissions have different driving effects in different periods and that changes in domestic input structures have become the main reason for the decline in global carbon emissions in the last 5 years. Cranston and Hammond (2010) selected four different scenarios to assess the possible changes in carbon emissions up to the end of the twenty first century and found that economic wealth was the most important driver of $\mathrm{CO}_{2}$ emissions in industrialized countries in the twenty first century.

It is easy to see that scholars have paid more attention to country- and region-specific than global-level studies on the factors influencing carbon emissions. To achieve global carbon emission reduction, not only country-specific and region-specific measures are needed, but also overall control and coordinated measures at the global level are required.

\section{The research method of carbon emission influencing factors}

In terms of research methods, there are two major widely used methods. One is the decomposition method, represented by structural decomposition analysis (SDA) (Guo et al. 2020; Jiang et al. 2021), index decomposition analysis (IDA) (Yang et al. 2013; Dong et al. 2010), and production decomposition analysis (PDA) (Liu et al. 2017). In recent years, many scholars have also optimized and improved the decomposition methods to have better applicability. For example, the decomposition method combined with the extended Kaya equation (Zhang et al. 2013) and the logarithmic mean Divisia index (LMDI) method based on the improved IDA method (Lin and Long 2016; Zhu and Du 2019; Chong et al. 2019; Chen et al. 2020), which are used to analyze the relative contribution of predetermined factors to the change of indicators and are especially applied in studies of carbon emissions related to energy and industry.

However, the decomposition method also has some drawbacks. It is often based on input-output models, the input-output tables on which it is based are not updated annually, and the application of the input-output method also has assumptions that may not actually be satisfied. In 
addition, the SDA approach requires high data requirements and is often difficult to apply in practice. IDA has major limitations in terms of economic explanatory power because it does not take into account factors such as technological progress and efficiency changes. Although PDA has a good economic basis, it does not reflect the heterogeneity of different energy inputs and outputs and may lead to conclusions that are contrary to reality (Wang 2011).

The second is to quantify the degree of influence of drivers through a series of econometric methods, represented by models based on IPAT and its extensions (Wang et al. 2017; Zhao and Gou 2013), as well as spatial econometric techniques (Tong et al. 2016, 2018) and ridge regression (Zhao and Yan 2013; Wen and Shao 2019). IPAT and its extension methods combined with econometric techniques can well quantify the specific contributions of multiple drivers and are widely used for the identification of carbon emission impact factors, and the improved STIRPAT model can easily introduce new variables with great elasticity. In addition, econometric techniques such as quantile regression and Logit regression are also widely used (Zheng et al. 2021; Pan et al. 2020).

Therefore, it can be seen that the existing literature on the factors influencing carbon emissions mainly has the following characteristics. First, there are more extensive studies on the drivers of $\mathrm{CO}_{2}$ emissions in single countries and regions, but relatively little attention has been paid to them at the global level, and few studies have focused on country differences in different regions. Second, less attention has been paid to the possible impact on carbon emissions caused by changes in other characteristics of the population besides population size. In addition, insufficient attention to data characteristics may lead to bias. Therefore, based on the STIRPAT model, this paper explores the possible driving effects of two demographic-related variables, nurturing pressure and unemployment, on $\mathrm{CO}_{2}$ emissions and tries to explain the long-term changes in carbon emissions from the perspective of non-traditional factors.

\section{Research hypothesis}

Some scholars have studied the effect of age structure changes on $\mathrm{CO}_{2}$ emissions. Changes in age structure may affect $\mathrm{CO}_{2}$ emissions through three channels. First, an increase in the proportion of the nurturing population will reduce the proportion of the working population, slowing economic growth and leading to lower $\mathrm{CO}_{2}$ emissions. Second, the uncertainty of the future due to the lack and inadequacy of the nurturing security system will increase the hidden costs of nurturing and psychological stress, which will lead to a reduction in spending and lower overall consumption levels, resulting in lower carbon emissions. Finally, a nurturing population may consume more resources in health care and other supporting areas, leading to increased $\mathrm{CO}_{2}$ emissions. Therefore, the effect of nurturing pressure on $\mathrm{CO}_{2}$ emissions depends on the combination of the above three aspects.

Considering the global level, we argue that the negative effect of nurturing pressure on $\mathrm{CO}_{2}$ emissions is greater than the positive one, because the effect of economic factors on carbon emissions has been shown to be pervasive and quite significant and has even become one of the most important drivers of carbon emissions with immediacy. For example, the $6.3 \%$ decline in global $\mathrm{CO}_{2}$ emissions in 2020 is largely due to the global economic impact of the COVID19 that year ( $\mathrm{Li}$ and $\mathrm{Li} 2021$ ). Clearly, the consumption of resources in healthcare and other supporting areas does not affect carbon emissions to the same extent as the impact of economic factors on carbon emissions. In addition, except for a few developed countries and most developing countries and regions, the nurturing security system still needs to be improved, and resources such as medical care are relatively scarce products, so the promotion of carbon emissions by related industries due to nurturing pressure is limited.

Further, our study also wants to focus on regional-level heterogeneity. The economic development level of each region of the world is not the same, and the nurturing pressure faced by each region is also heterogeneous. In addition, there is a great difference in the soundness of the conservation protection system in different countries and regions, so the specific direction and degree of influence of conservation pressure on $\mathrm{CO}_{2}$ emissions should be different in different regions. Based on the above analysis, two hypotheses are proposed in this paper:

Hypothesis 1: At the global level, nurturing pressure has a negative effect on $\mathrm{CO}_{2}$ emissions.

Hypothesis 2: At the regional level, the effect of nurturing pressure on $\mathrm{CO}_{2}$ emissions is heterogeneous.

In addition to nurturing pressure, this paper aims to analyze the response of $\mathrm{CO}_{2}$ emissions to unemployment. According to the United Nations International Labor Organization (ILO), the total number of unemployed people worldwide is expected to reach 205 million in 2022, significantly more than the 187 million in 2019, and the global unemployment rate will reach 5.7\% (Berg et al. 2021). Unemployment is known to cause a range of social problems such as poverty, rising inequality, and social unrest, but its impact on the environment is often overlooked. On the one hand, unemployment implies a restriction on personal income sources, thus creating a constraint on consumption behavior and reducing $\mathrm{CO}_{2}$ emission levels. On the other hand, the integrity of the unemployment protection system affects the optimism of the unemployed or potentially unemployed about their future life and their consumption behavior. The lack of a well-established unemployment protection system tends to make people have pessimistic 
psychological expectations and curtail their consumption, thus producing less $\mathrm{CO}_{2}$ emissions.

Generally, given the range of social impacts that unemployment can cause, governments tend not to ignore it. In addition to measures such as granting benefits and unemployment insurance, government-led public work projects and other measures intended to create more jobs are often used to relieve unemployment pressure, thus creating a positive driver of $\mathrm{CO}_{2}$ emissions in the process of solving the unemployment problem. According to the ILO report, the global unemployment problem is not optimistic. The unstoppable globalization of the economy has exacerbated the global impact of economic and financial problems, and many governments have not been able to solve the unemployment problem well or to balance economic growth and unemployment reduction at the same time. Therefore, considering the global level, we believe that unemployment has a negative impact on global $\mathrm{CO}_{2}$ emissions. However, given the different levels of economic development and the different attitudes and governance capabilities of governments in facing the unemployment problem in each region, the impact of unemployment on carbon emissions should be heterogeneous at the regional level. Based on the above analysis, the third and fourth hypotheses are proposed in this paper:

Hypothesis 3: At the global level, the increase in unemployment has a negative impact on $\mathrm{CO}_{2}$ emissions.

Hypothesis 4: At the regional level, the effect of unemployment on $\mathrm{CO}_{2}$ emissions is heterogeneous.

Figure 1 shows the possible pathways through which nurturing pressure and unemployment affect $\mathrm{CO}_{2}$ emissions, and we will explore the specific effects at both the global and regional levels later in the paper.

\section{Methodology and data}

\section{STIRPAT model}

The IPAT model can initially be traced back to the equation $I=P F$ proposed by Holdren and Ehrlich (1972), in which $I$ denotes environmental stress, $P$ denotes population size,

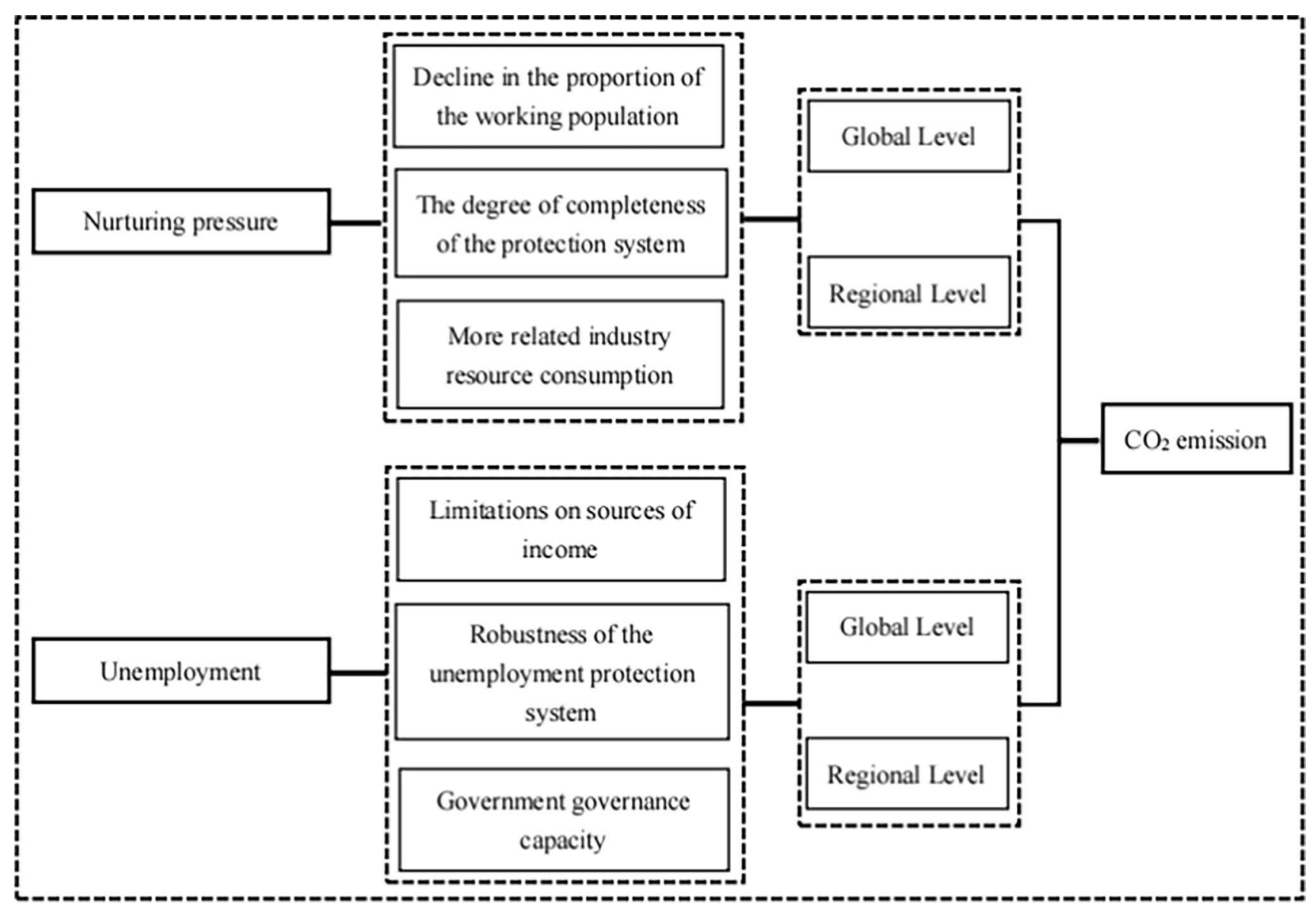

Fig. 1 Possible pathways by which nurturing pressure and unemployment affect $\mathrm{CO}_{2}$ emissions 
and $F$ denotes per capita environmental stress. It was subsequently developed and improved by scholars, and Commoner (1990) proposed the classical IPAT model based on it:

$I=P^{*} A^{*} T$

The model suggests that changes in the environment are mainly due to the combination of population size $P$, affluence (per capita consumption or per capita production) $A$, and technology (environmental impact per unit of energy consumption or per unit of production) $T$ and has since been widely used as an analytical framework for the drivers of environmental change. The main advantage of this analytical framework is that it describes the important drivers of environmental change in a concise way and clearly identifies the relationship between these three drivers and environmental pressures through an equation. At the same time, the multiplicative form of the drivers implies that the effects of the variables are not completely independent of each other.

However, this form of concise mathematical constancy equation also makes the IPAT model to have some key limitations. One is that it does not allow for statistically significant hypothesis testing, since the form of the equation makes the value of the missing term determined by the value of the known term. Second, it also assumes a priori that the functional relationship between drivers and environmental impacts is proportional, thus making it easy to ignore non-monotonic or non-proportional effects of the driving influences (York et al. 2003). To overcome these shortcomings, Dietz and Rosa (1994) proposed a stochastic impact by regression on population, affluence, and technology (STIRPAT model). The model forms are as follows.

$I_{i t}=a_{i} P_{i t}^{b} A_{i t}^{c} T_{i t}^{d} e_{i t}$

where $a$ is the constant term of the model; $P, A$, and $T$ have the same meaning as in the IPAT model; $b, c$, and $d$ are the exponential terms of $P, A$, and $T$, respectively, and can be estimated; $e$ is the error term in the model; and the subscript $i$ indicates that $I, P, A, T$, and $e$ vary with the observed units. When $a=b=c=d=1$, the STIRPAT model is transformed into the IPAT model, and therefore, the IPAT model can be considered as a special form of the STIRPAT model. In practical use, the original STIRPAT model, which is a multivariate nonlinear model, is usually logarithmically linearized. There are two advantages to doing this: it facilitates the estimation and hypothesis testing of the equations, and it reduces the possibility of heteroskedasticity in the subsequent econometric analysis. The specific form of the conversion is as follows: $\ln I_{i t}=a_{i}+b \ln P_{i t}+c \ln A_{i t}+d \ln T_{i t}+e_{i t}$

\section{Panel unit root, cross-sectional correlation, within-group autocorrelation, and between-group heteroskedasticity tests}

As a combination of cross-sectional and time series data, panel data facilitate the reduction of covariance in explanatory variables and not only provide more information but also make it easy to obtain more valid estimates. However, several problems often arise when performing estimation of panel data models. The first is the cross-sectional correlation that emerges from the correlation of random perturbation terms for different individuals at the same time. Second is the intra-group autocorrelation arising from the correlation of different random perturbation terms for the same individual, and third is the inter-group heteroskedasticity arising from the different variance of different individual perturbation terms. The application of traditional panel data models tends to default to correlation and cross-sectional independence among observed individuals at different times, and this assumption is often difficult to achieve in practice. The presence of within-group autocorrelation and between-group heteroskedasticity also affects the degree of standardization of traditional panel model estimates. Therefore, this article intends to test the cross-sectional correlation of the data first.

To ensure the accuracy of the tests, the LM test statistic proposed by Breusch and Pagan (1980), the bias-adjusted LM statistic proposed by Pesaran et al. (2008), and the CD crosssectional correlation test statistic proposed by Pesaran (2004) were calculated separately. Wooldridge test statistic (Wooldridge 2010) and modified Wald test statistic (Lütkepohl and Burda, 1997) were used for within-group autocorrelation and between-group heteroskedasticity tests, respectively.

The degree of non-stationarity of the time series should be measured. In order to examine the data characteristics and avoid pseudo-regressions, a panel unit root test must be performed (Ullah et al., 2020). The panel unit root test developed from the time series unit root test uses the cross-sectional dimensional information in the panel framework to construct the test statistic, which has stronger testing power than the time series unit root test. Although traditional first-generation panel unit root tests such as LLC test, IPS test, Fisher test, etc. are useful for improving the test efficacy by considering crosssectional dimensional information, they often have strong subjective assumptions of cross-sectional independence, which often lead to significant bias (Palm et al. 2011). 
Table 1 Description of variables

\begin{tabular}{lll}
\hline Abbreviation & Meaning & Description \\
\hline $\mathrm{C}$ & $\mathrm{CO}_{2}$ emissions & Million tons of $\mathrm{CO}_{2}$ \\
$\mathrm{PS}$ & Population size & Year-end population \\
$\mathrm{GDP}$ & Per capita GDP & At constant 2017 purchasing power parity (PPP) \\
$\mathrm{EI}$ & Energy intensity & Total energy consumption (kg oil equivalent)/total GDP \\
$\mathrm{PUP}$ & Percentage of urban population & Urban population/total population \\
ADR & Age dependency ratio & Percentage of population aged 14 years and younger \\
& & and 65 years and older \\
UR & Unemployment rate & Unemployed population/labor force population \\
\hline
\end{tabular}

The second-generation panel unit root test CIPS, developed on the basis of the first-generation panel unit root, takes into account the heterogeneity component, which helps to overcome the existence of cross-sectional correlation problem and enhances the reliability of the test (Pesaran 2007; Weimin et al. 2021). In this paper, we will choose the appropriate test based on data characteristics and panel fitness.

\section{Panel cointegration test}

If the results based on the unit root test indicate that the variables are cointegrated with each other of the same order, then a cointegration test can be performed as a way to determine whether there is a long-run cointegration relationship between the variables, which in turn provides a reference for the selection of the subsequent estimation methods. Kao (1999) proposed a method for testing panel cointegration using the extended DF and ADF tests, using the residuals from static panel regressions to construct the statistic. However, the asymptotic distribution of this test statistic proved not to be an excellent approximation of its empirical distribution and was not applicable to test the cointegration of cross-sectionally correlated panel data (Westerlund and Edgerton, 2007). Pedroni (2004) proposed a residualbased cointegration test statistic for panel data with the null hypotheses of no cointegration relationship, which allows for the presence of heterogeneous panels. Westerlund (2005) further developed the test by proposing a residual-based cointegration test for panel data that is nonparametric in nature and does not require consideration of any correction for current period correlation. This test was shown to have high stability and reliability when the error term has cross-sectional dependence (Kapetanios et al., 2011).

\section{Parameter estimation methods}

The panel corrected standard errors (PCSE) estimation method introduced by Beck and Katz (1995) is an innovation in the estimation of panel data models, which can effectively handle complex panel structures and allow for the existence of heteroskedasticity in different crosssections. PCSE also effectively handles serial and contemporaneous correlations in the perturbation terms and is well adapted to non-equilibrium panels. The standard error-adjusted robust estimation (Driscoll-Kraay F. E. Estimation) proposed by Driscoll and Kraay (1998) proved to be advantageous in the face of data with simultaneous within-group autocorrelation, between-group contemporaneous correlation, and between-group heteroskedasticity. This method was used in this study to check the robustness of the PCSE estimates. Since all estimation methods have only relative accuracy but not absolute accuracy qualitatively, the analysis in this paper is based on a combination of the above estimation methods.

\section{Data}

Referring to previous studies (Chontanawat 2018; Li et al. 2018; Dong et al. 2019), $P$ in this paper is measured by population size, GDP per capita to measure affluence $A$, and energy intensity to measure $T$. Based on the ordinary STIRPAT model, this paper introduces two critical variables, age dependency ratio and unemployment rate, to explore how the possible nurturing pressure and unemployment on the population of countries and regions will affect the level of global $\mathrm{CO}_{2}$ emissions. In addition, referring to other studies, urban population share is added to reflect the driving effect of urbanization process and level in countries and regions. Based on the above considerations, the model is rewritten as follows, and the specific variable choices and meanings are shown in Table 1:

$\ln C_{i t}=a_{i}+b \ln P S_{i t}+c \ln G D P_{i t}+d \ln E I_{i t}+e \ln P U P_{i t}+f \ln A D R_{i t}+g \ln U R_{i t}+e_{i t}$ 

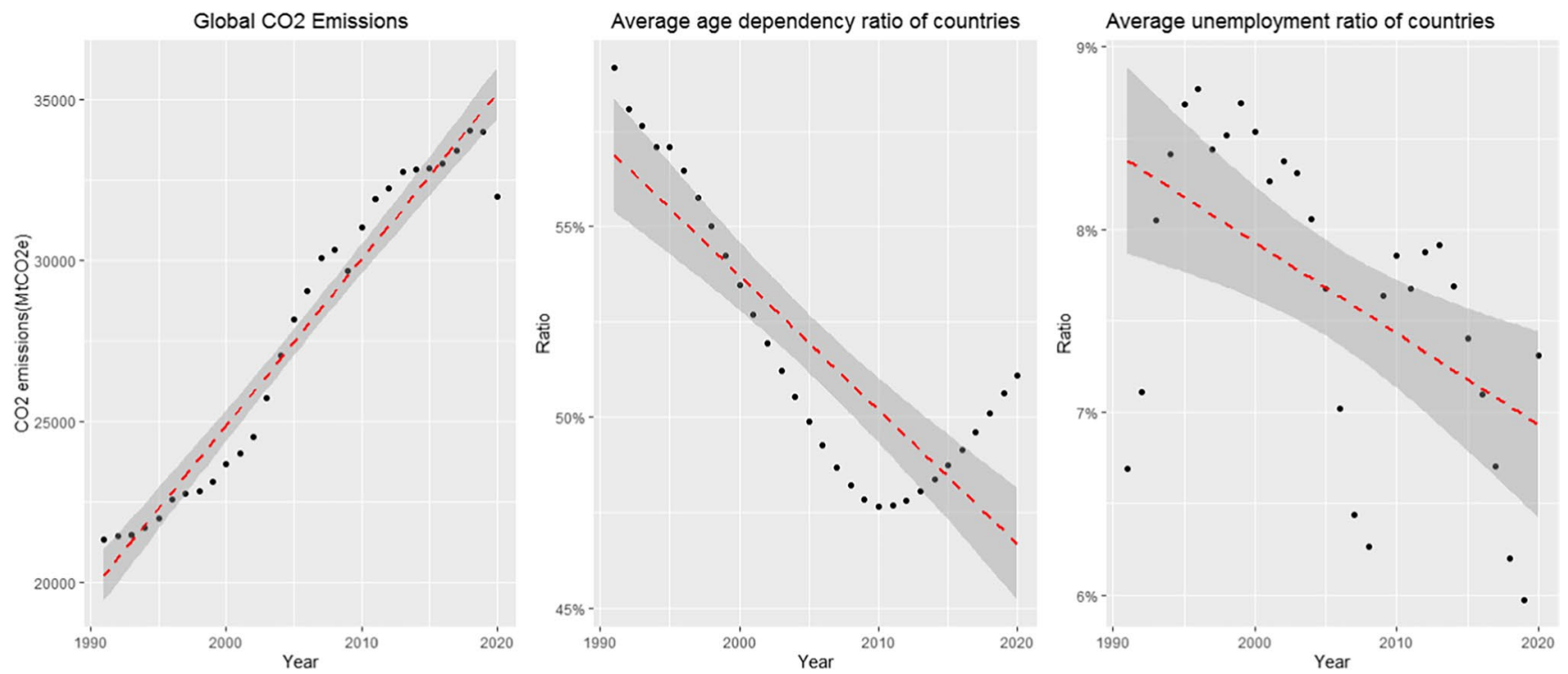

Fig. 2 Scatterplot of global $\mathrm{CO}_{2}$, ADR, and UR changes 1991-2020

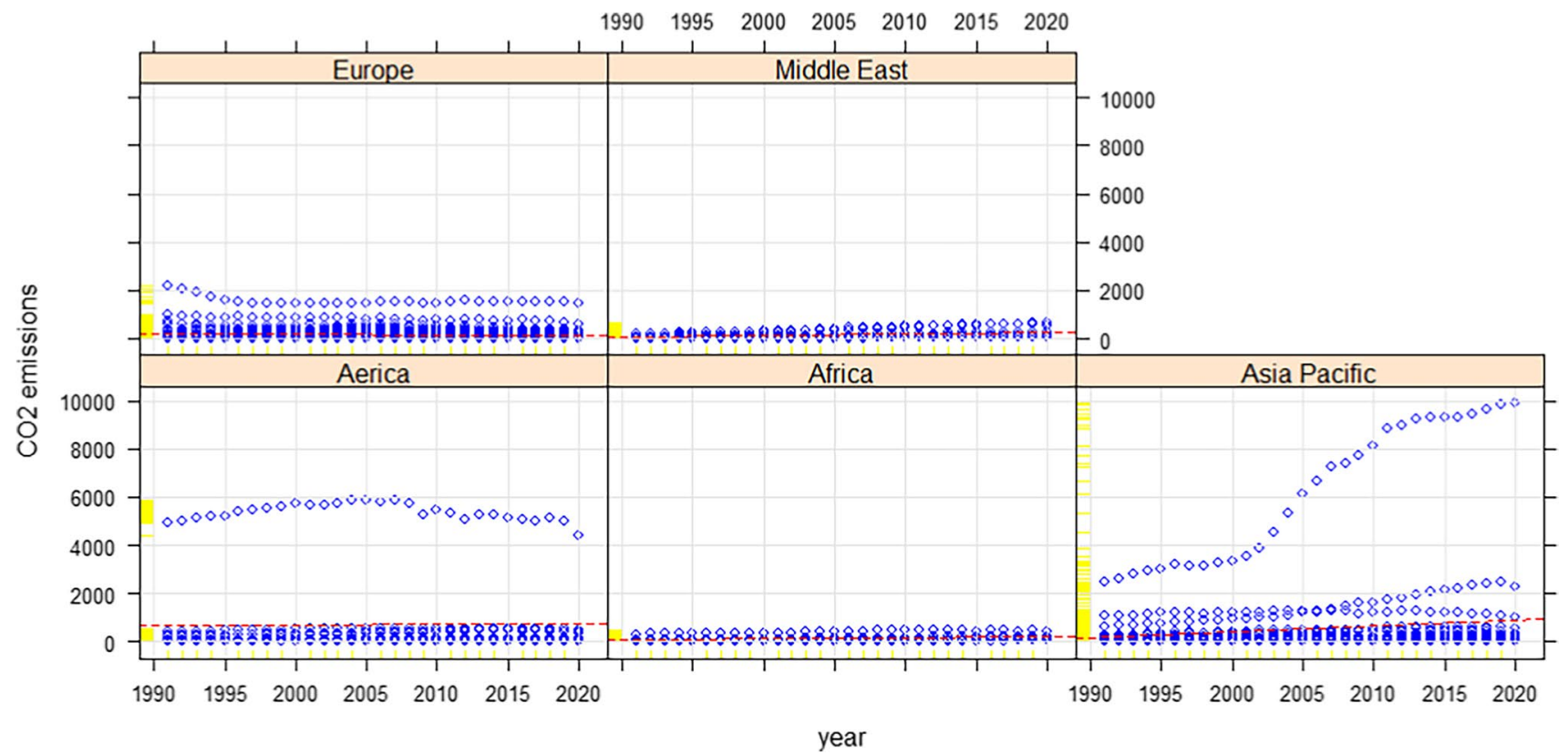

Fig. $3 \mathrm{CO}_{2}$ emissions in Europe, Middle East, Americas, Africa, and Asia-Pacific, 1991-2020

In view of the small size of some countries and regions and the serious lack of relevant data, this paper selects data for 77 countries and regions with relatively complete data from 1991 to 2020. All data are sourced from the official website of the World Bank (IBRD) and the BP Statistical Yearbook. In addition, due to data access problems, data for some variables are missing, so this paper uses unbalanced panel data. In order to explore the different characteristics that different regional panels may present, the global panel is further divided into five sub-panels, Africa, the Americas, Asia-Pacific, Europe, and the Middle East, based on the geographical location of each country, and explored at the global and regional levels respectively. 


\section{Empirical results}

\section{Descriptive statistical analysis}

In order to provide an overall picture of global $\mathrm{CO}_{2}$ emissions, the data has been collated, and the following overview graphs of the relevant variables have been created. Figure 1 shows the change in total $\mathrm{CO}_{2}$ emissions for 77 countries and regions between 1991 and 2020, confirming the large volume of global $\mathrm{CO}_{2}$ emissions, which have generally shown a relatively steady increase over the 30 -year period, with a relatively rapid increase between 2000 and 2010. Further, Fig. 3 visualizes global carbon emissions by five different regions.

We found that among the different geographical regions in our study, Europe, Asia-Pacific, and the Americas have relatively high carbon emissions, while Africa and the Middle East countries have relatively low emissions. The yellow carpet plot facets of the graph show that Asia-Pacific, Europe, and the Americas have a greater dispersion of $\mathrm{CO}_{2}$ emissions than Africa and the Middle East. We also find that there are two clear outliers among the Asia-Pacific and the Americas: China and the USA. Having such high carbon emissions may be related to their huge population size and economic volume. With the exception of China, where carbon emissions fluctuate more markedly over the study period, the fluctuations in carbon emissions over the 30-year period are generally more moderate. On this basis, there is a slow downward trend in $\mathrm{CO}_{2}$ emissions for European countries as a whole and a slow upward trend for Asia-Pacific countries and regions.

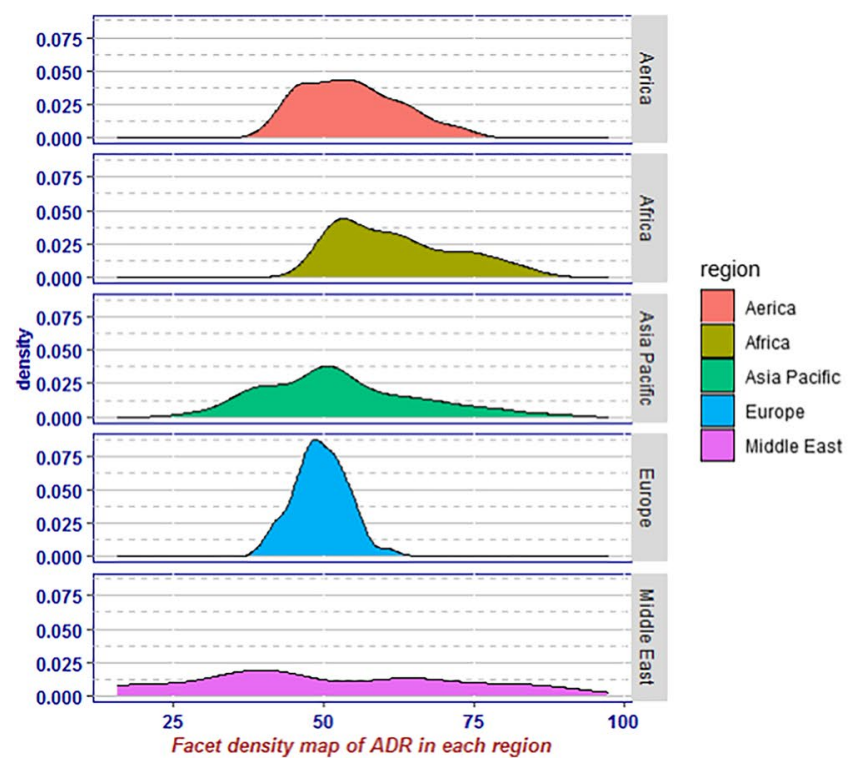

In addition, Figs. 2 shows the movement of the average ADR and UR for the 77 countries and regions included in the sample of this paper. The scatterplot shows that the average ADR has not followed a linear trend over the 30-year period but has been characterized by a more pronounced quadratic curve. Since 1990, the proportion of the population under 14 and over 65 years of age who are of dependent age has been declining, from nearly $60 \%$ in 1990 to $47 \%$ in 2010 , and has been trending upwards again in the following decade. By 2020, the global average ADR rises to 51.1\%. The global average unemployment rate, on the other hand, has fluctuated in a range of 6-9\% over this 30-year period, and the employment situation is not optimistic.

To further explore the different characteristics of ADR and UR across continents, we plotted the density profiles of them at the average level of each region as shown in Fig. 4. Among the five regions delineated in this paper, ADR in the Asia-Pacific and European regions is generally concentrated around 50\%, with relatively obvious normal distribution characteristics. In Africa and the Americas, the ratios are slightly higher and have a more pronounced right-skewed distribution. The European countries have the most similar dependency ratios of the five regions, while the Middle Eastern countries have more varied ADR. On the other hand, the density profile of the UR shows that, with the exception of Africa, all four regions have a more pronounced right-skewed distribution of UR, with Asia-Pacific having the lowest unemployment rate and a smaller gap between countries and regions and Africa having the highest unemployment rate and the largest gap between countries.

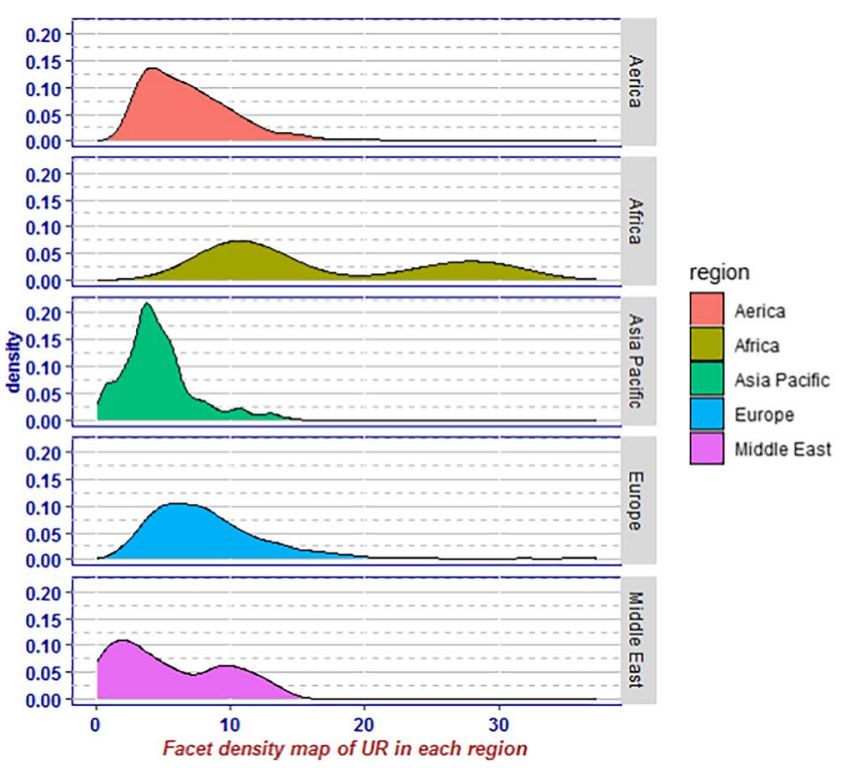

Fig. 4 ADR and UR density by region, 1991-2020 


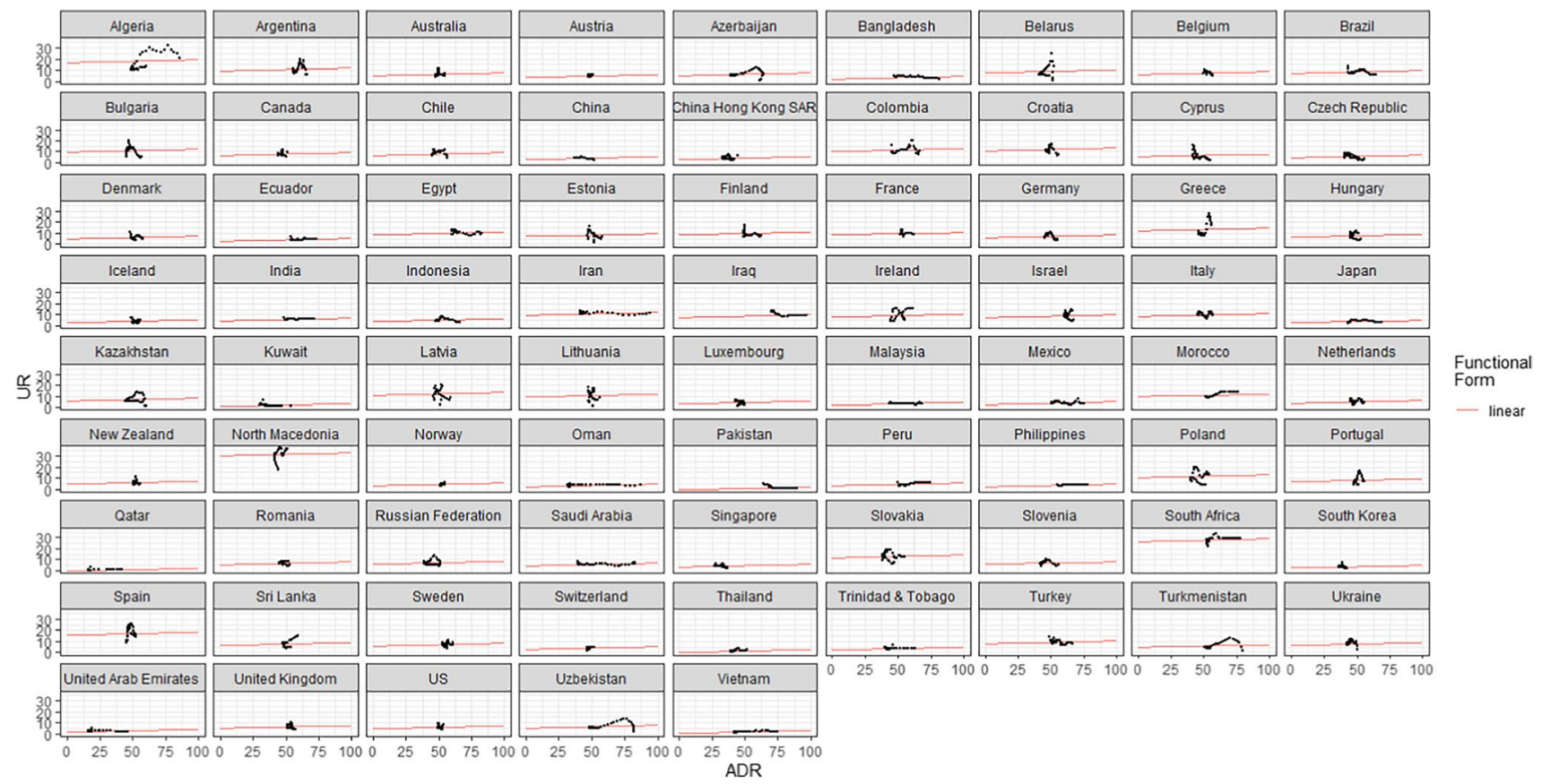

Fig. 5 Scatterplot of ADR and UR by country

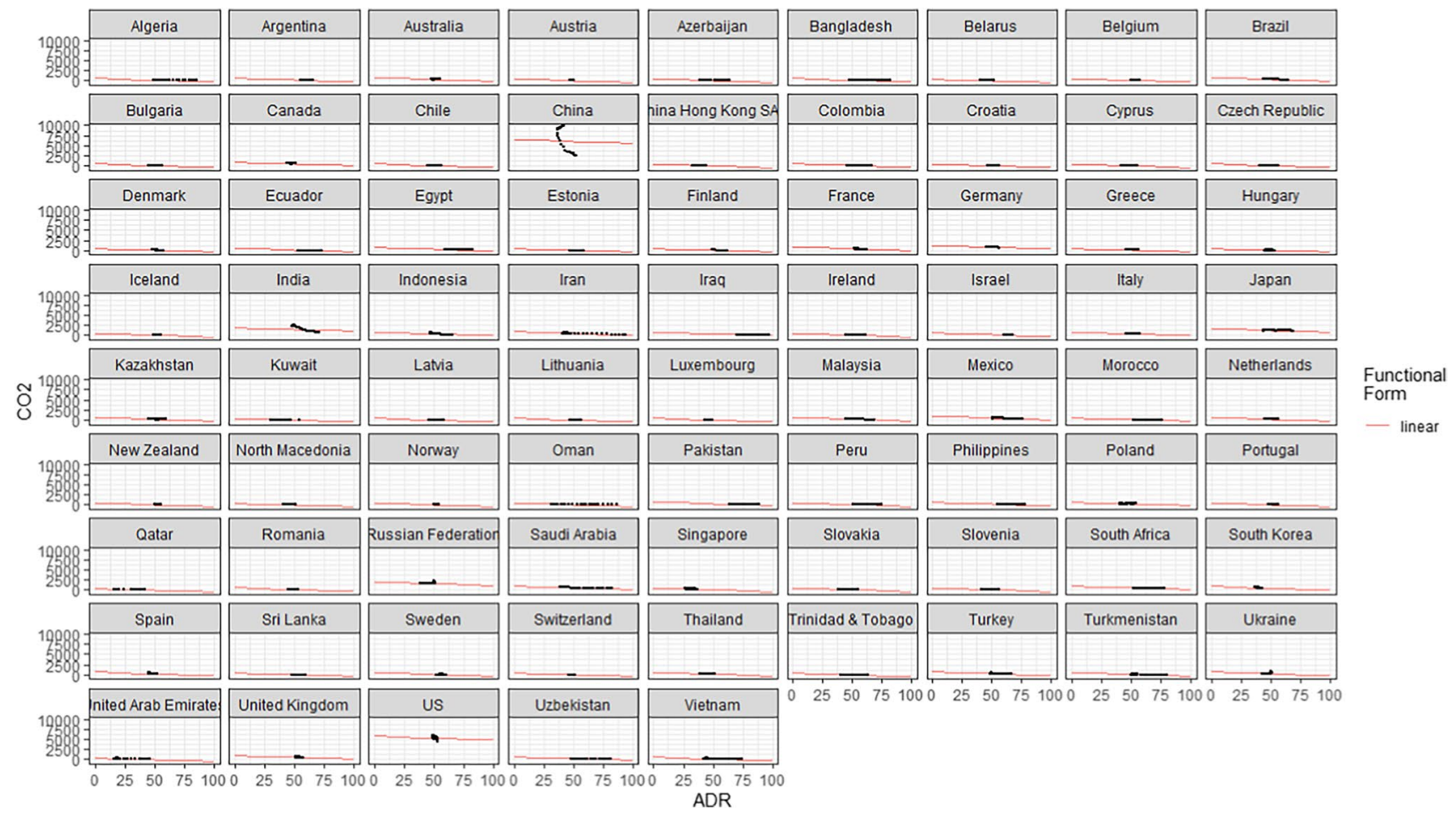

Fig. 6 Scatterplot of ADR and $\mathrm{CO}_{2}$ emissions by country

Figure 5 shows a graph of the relationship between the ADR and the UR for each country in the global panel explored in this paper. The horizontal axis represents the ADR, and the vertical axis represents the UR. The graph visually shows that the relationship between ADR and UR shows large differences across countries and 


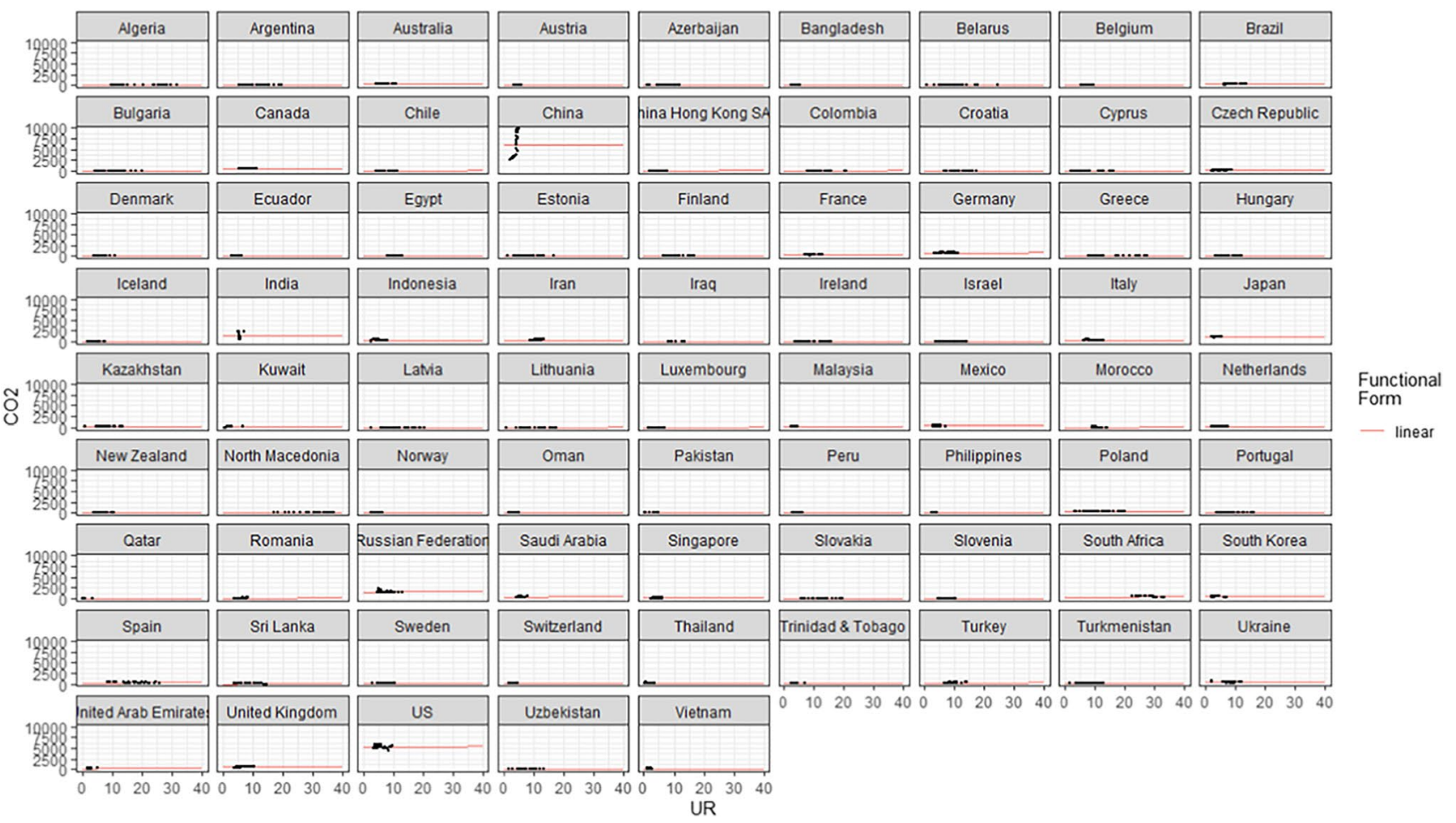

Fig. 7 Scatterplot of UR and $\mathrm{CO}_{2}$ emissions by country

regions. In some countries, the lower unemployment rate is accompanied by lower nurturing pressure, such as Qatar and the United Arab Emirates, while others have both high UR and high ADR, such as South Africa and Algeria. Some countries have more stable UR and significantly higher ADR; examples include Japan, Vietnam, and the Philippines.

Figure 6 shows the relationship between ADR and $\mathrm{CO}_{2}$ emissions for each country. The horizontal axis represents the ADR, and the vertical axis represents $\mathrm{CO}_{2}$ emissions. As can be seen, in most countries and regions, higher ADR seems to imply lower $\mathrm{CO}_{2}$ emissions, and lower ADR seems to imply higher $\mathrm{CO}_{2}$ emissions. The lower carbon consumption patterns of the dependent population relative to the working population may have contributed to this result (Yang and Wang 2020). Figure 7 shows the relationship between UR and $\mathrm{CO}_{2}$ emissions across countries and regions. The horizontal axis represents the UR, and the vertical axis represents $\mathrm{CO}_{2}$ emissions. Looking at the graphs alone, there is no particularly clear synergistic trend between changes in UR and $\mathrm{CO}_{2}$ emissions for most countries and regions, which will be explored in more detail and with statistical significance in later sections of this paper.

\section{Cross-sectional correlation, within-group autocorrelation, and between-group heteroscedasticity tests}

With the deepening of globalization, rapid development of international trade, accelerated circulation of economic factors across countries, and continuous technological advances, economic variables are often not independent of each other but show a tendency to influence or co-evolve with each other. Pesaran points out that ignoring the correlation of individual panel data cross-sections is likely to lead to large differences between the estimated results of panel data models and the real situation (Pesaran, 2007). The results of all three tests indicate that there is significant cross-sectional correlation in panel data at the global level as well as at each regional level. The paper also tests for possible autocorrelation, and the results show that there is within-group autocorrelation for both the global and the country samples by different regions. Similarly, if there is between-group heteroscedasticity in the panel data, then there also generates bias in the estimation of the parameters, and the test result of between-group heteroscedasticity significantly rejects the original hypothesis of no heteroscedasticity, indicating that there is significant heteroscedasticity within the sample. Table 2 shows the results of the specific tests. 
Table 2 Results of cross-sectional correlation, intra-group autocorrelation, and between-group heteroscedasticity test

\begin{tabular}{|c|c|c|c|c|c|}
\hline \multirow[b]{2}{*}{ Scope } & \multicolumn{3}{|c|}{ Cross-sectional correlation test } & \multirow{2}{*}{$\begin{array}{l}\text { Intra-group autocor- } \\
\text { relation test } \\
\text { Wooldridge test }\end{array}$} & \multirow{2}{*}{$\begin{array}{l}\text { Between groups } \\
\text { heteroscedastic- } \\
\text { ity test } \\
\text { Modified Wald test }\end{array}$} \\
\hline & Breusch-Pagan LM & Pesaran scaled LM & Pesaran CD & & \\
\hline Global & $29,787.11 * * *$ & $351.1331 * * *$ & $8.8328 * * *$ & $41.947 * * *$ & $1.5 \mathrm{e}+05 * * *$ \\
\hline Africa & $23.1525 * * *$ & $4.9515 * * *$ & $-2.2279 * *$ & $10.766 * *$ & $224.51 * * *$ \\
\hline America & $419.5492 * * *$ & $39.4809 * * *$ & $-2.8897 * *$ & $67.632 * * *$ & $936.72 * * *$ \\
\hline Asia-Pacific & $1903.07 * * *$ & $87.8786 * * *$ & $4.5395^{* * *}$ & $8.04 * *$ & $6791.51 * * *$ \\
\hline Europe & $5572.902 * * *$ & $150.099 * * *$ & $7.0677 * * *$ & $33.682 * * *$ & $2397.86 * * *$ \\
\hline Middle East & $255.4714 * * *$ & $30.3971 * * *$ & $-2.6764 * *$ & $98.618 * * *$ & $426.75^{* * *}$ \\
\hline
\end{tabular}

Note: $* * *$, and $* * *$ denote significance at the $1 \%, 5 \%$, and $10 \%$ levels, the null hypothesis of cross-sectional correlation test is no crosssectional correlation, the null hypothesis of within-group autocorrelation test is no within-group autocorrelation, and the null hypothesis of between-group heteroscedasticity test is no between-group heteroscedasticity

Table 3 Panel CIPS unit root test results

\begin{tabular}{|c|c|c|c|c|c|}
\hline \multirow[b]{2}{*}{ Scope } & \multirow[b]{2}{*}{ Variables } & \multicolumn{2}{|l|}{ Level } & \multicolumn{2}{|l|}{ 1st difference } \\
\hline & & Individual & Individual and trend & Individual & Individual and trend \\
\hline \multirow[t]{7}{*}{ Global } & $\operatorname{lnCO} 2$ & -1.1458 & -1.9808 & $-2.3654 * * *$ & $-2.6213 * *$ \\
\hline & $\ln \mathrm{P}$ & $-1.4584^{*}$ & -1.5564 & $-1.9167 * * *$ & $-2.2949 *$ \\
\hline & $\operatorname{lnGDP}$ & -0.6726 & -2.203 & $-2.211 * * *$ & $-2.1322 *$ \\
\hline & $\ln E I$ & -1.3717 & -1.8737 & $-2.5378 * * *$ & $-2.9717 * * *$ \\
\hline & $\operatorname{lnPUP}$ & -0.90862 & -1.688 & $-1.3823^{*}$ & $-2.9398 * * *$ \\
\hline & $\ln \mathrm{ADR}$ & -0.95247 & -2.2065 & $-1.5656 * *$ & $-3.2178 * * *$ \\
\hline & $\operatorname{lnUR}$ & $-1.8816^{* *}$ & -2.2956 & $-2.5284 * * *$ & $-2.6201 * *$ \\
\hline \multirow[t]{7}{*}{ America } & $\operatorname{lnCO} 2$ & -0.7360 & -1.2251 & $-2.3619 * * *$ & $-3.9828 * * *$ \\
\hline & $\ln \mathrm{P}$ & -1.505 & -2.1502 & $-2.3801 * * *$ & $-4.6074 * * *$ \\
\hline & $\operatorname{lnGDP}$ & $-1.7842 * *$ & -1.8699 & $-1.8517 * *$ & $-2.8187 * *$ \\
\hline & $\operatorname{lnEI}$ & -1.5115 & -1.9132 & $-2.4762 * * *$ & $-3.2345 * * *$ \\
\hline & $\operatorname{lnPUP}$ & $-1.6981^{*}$ & -2.6505 & $-1.7184 *$ & $-3.1142 * *$ \\
\hline & $\ln \mathrm{ADR}$ & $-2.2085^{* * *}$ & -2.0678 & $-1.7606 * *$ & -2.2687 \\
\hline & $\operatorname{lnUR}$ & $-2.4396 * * *$ & -2.3012 & $-2.5988 * * *$ & $-2.9263 * *$ \\
\hline \multirow[t]{7}{*}{ Asia-Pacific } & $\operatorname{lnCO}_{2}$ & -1.4804 & -2.1976 & $-2.3464 * * *$ & $-3.5407 * * *$ \\
\hline & $\ln \mathrm{P}$ & -0.2015 & $-2.9433 * * *$ & $-1.8449 * * *$ & $-5.3005^{* * *} *$ \\
\hline & $\operatorname{lnGDP}$ & -1.181 & -2.578 & $-2.7884 * * *$ & -2.6066 \\
\hline & $\operatorname{lnEI}$ & -1.469 & -2.1334 & $-1.9725 * * *$ & $-2.68 *$ \\
\hline & $\operatorname{lnPUP}$ & -1.2555 & -2.2723 & -1.1398 & -2.3414 \\
\hline & $\ln A D R$ & -0.8184 & -2.0678 & -1.3694 & $-3.5985^{* * *}$ \\
\hline & $\ln U R$ & $-2.3406 * * *$ & $-3.0577 * * *$ & $-3.0374 * * *$ & $-3.2913 * * *$ \\
\hline \multirow[t]{7}{*}{ Europe } & $\operatorname{lnCO} 2$ & $-1.66^{* *}$ & -2.0155 & $-2.4407 * * *$ & $-3.9783 * * *$ \\
\hline & $\ln \mathrm{P}$ & -0.6660 & -2.2383 & $-2.3584 * * *$ & $-3.1415^{* * *}$ \\
\hline & $\operatorname{lnGDP}$ & -0.4331 & $-2.5855^{*}$ & $-2.2827 * * *$ & $-2.7941^{* *}$ \\
\hline & $\ln E I$ & -1.4383 & -1.5688 & $-2.9073 * * *$ & $-3.0148 * * *$ \\
\hline & $\operatorname{lnPUP}$ & -0.9748 & -1.2384 & -1.3871 & $-2.4980^{*}$ \\
\hline & $\ln \mathrm{ADR}$ & -1.3448 & -2.5149 & $-1.7999 * * *$ & $-2.637 * *$ \\
\hline & $\ln U R$ & $-1.9699 * * *$ & $-2.6357 *$ & $-2.5895 * * *$ & $-2.8388 * * *$ \\
\hline
\end{tabular}

Note:*,**, and $* * *$ denote significance at the $1 \%, 5 \%$, and $10 \%$ levels, respectively, to test the null hypothesis of the existence of a unit root 
Table 4 IPS, Fisher ADF, and Fisher ADF panel unit root test results

\begin{tabular}{|c|c|c|c|c|c|}
\hline \multirow[b]{2}{*}{ Variables } & \multirow[b]{2}{*}{ Test statistics } & \multicolumn{2}{|l|}{ Level } & \multicolumn{2}{|l|}{ 1st difference } \\
\hline & & Individual & Individual and trend & Individual & Individual and trend \\
\hline \multicolumn{6}{|c|}{ Middle East } \\
\hline \multirow[t]{3}{*}{$\operatorname{lnCO}_{2}$} & IPS & -1.0558 & -0.2155 & $-7.9613 * * *$ & $-9.9901 * * *$ \\
\hline & Fisher ADF & $34.687^{*}$ & 15.203 & $86.759 * * *$ & $100.147 * * *$ \\
\hline & Fisher PP & $63.716 * * *$ & 17.883 & $106.789 * * *$ & $443.070 * * *$ \\
\hline \multirow[t]{3}{*}{$\ln P$} & IPS & 0.4971 & $-5.7532 * * *$ & $-3.2225 * * *$ & 0.8140 \\
\hline & Fisher ADF & 11.306 & $58.5604 * * *$ & $34.8804 * * *$ & 12.331 \\
\hline & Fisher PP & 15.242 & 14.8735 & 19.8047 & 12.323 \\
\hline \multirow[t]{3}{*}{$\operatorname{lnGDP}$} & IPS & -0.6166 & 1.9316 & $-7.4489 * * *$ & $-7.1070 * * *$ \\
\hline & Fisher ADF & 15.2614 & 8.4669 & $76.292 * * *$ & $67.626 * * *$ \\
\hline & Fisher PP & 17.1735 & 6.3090 & $76.1536^{* * *}$ & $67.0364 * * *$ \\
\hline \multirow[t]{3}{*}{$\operatorname{lnEI}$} & IPS & -0.1147 & -0.7653 & $-9.4958 * * *$ & $-8.1461 * * *$ \\
\hline & Fisher ADF & 15.869 & 15.2768 & $100.070 * * *$ & $78.796^{* * *}$ \\
\hline & Fisher PP & 12.316 & 8.8637 & $101.400 * * *$ & $103.097 * * *$ \\
\hline \multirow[t]{3}{*}{$\operatorname{lnPUP}$} & IPS & -0.0538 & 0.15299 & $-18.6662 * * *$ & $-30.1242 * * *$ \\
\hline & Fisher ADF & $35.0746^{* *}$ & 18.7108 & $49.5191 * * *$ & $307.966 * * *$ \\
\hline & Fisher PP & 37.6099 & $73.4016^{* * *}$ & $43.4441 * * *$ & $283.375^{* * *}$ \\
\hline \multirow[t]{3}{*}{$\ln \mathrm{ADR}$} & IPS & 0.0930 & 1.3432 & $-9.6682 * * *$ & $-8.6587 * * *$ \\
\hline & Fisher ADF & 11.7269 & 6.1392 & $103.229 * * *$ & $83.5785 * * *$ \\
\hline & Fisher PP & 6.1563 & 2.5967 & $109.664 * * *$ & $91.8981 * * *$ \\
\hline \multirow[t]{3}{*}{$\operatorname{lnUR}$} & IPS & -1.505 & -0.2803 & $-4.3094 * * *$ & -0.7352 \\
\hline & Fisher ADF & $32.4118^{* *}$ & $21.810^{*}$ & $48.9417 * * *$ & $26.1706^{* *}$ \\
\hline & Fisher PP & 9.3560 & 3.9783 & $36.4059 * * *$ & $0.0123 * *$ \\
\hline \multicolumn{6}{|l|}{ Africa } \\
\hline \multirow[t]{3}{*}{$\ln \mathrm{CO}_{2}$} & IPS & 0.1018 & 2.2642 & $-6.1038 * * *$ & $-4.5678 * * *$ \\
\hline & Fisher ADF & 9.6072 & 6.5574 & $51.699 * * *$ & $35.4136 * * *$ \\
\hline & Fisher PP & 7.4096 & 6.9332 & $68.2380 * * *$ & $77.9538 * * *$ \\
\hline \multirow[t]{3}{*}{$\ln \mathrm{P}$} & IPS & -1.3979 & $-1.7913 * *$ & $-3.8529 * * *$ & $-3.2576^{* * *}$ \\
\hline & Fisher ADF & 11.505 & $17.083 * *$ & $30.7674 * * *$ & $24.605 * *$ \\
\hline & Fisher PP & 4.8844 & $13.8022 *$ & $16.8667 * *$ & 7.54371 \\
\hline \multirow[t]{3}{*}{$\operatorname{lnGDP}$} & IPS & -0.2802 & 2.2125 & $-4.3285^{* * *}$ & $-4.1039 * * *$ \\
\hline & Fisher ADF & 7.5406 & 5.7978 & $37.5639 * * *$ & $37.3799 * * *$ \\
\hline & Fisher PP & 1.9602 & 3.9463 & $36.929 * * *$ & $30.7938 * * *$ \\
\hline \multirow[t]{3}{*}{$\operatorname{lnEI}$} & IPS & 0.9003 & -0.6510 & $-6.6259 * * *$ & $-7.2113 * * *$ \\
\hline & Fisher ADF & 17.7384 & $25.6318 * *$ & $55.7733 * * *$ & $55.1565 * * *$ \\
\hline & Fisher PP & 17.5320 & $39.5996 * * *$ & 79.8766 *** & $150.532 * * *$ \\
\hline \multirow[t]{3}{*}{$\operatorname{lnPUP}$} & IPS & 0.4958 & 1.4197 & $-5.1312 * * *$ & $-4.3497 * * *$ \\
\hline & Fisher ADF & 10.0834 & 11.3538 & $39.2888 * * *$ & $31.2478 * * *$ \\
\hline & Fisher PP & $48.7583 * * *$ & 3.4630 & $39.1528 * * *$ & $31.0211 * * *$ \\
\hline \multirow[t]{3}{*}{$\ln A D R$} & IPS & $-6.9259 * * *$ & $-2.6574 * *$ & $-3.6481 * * *$ & $-2.0871^{* *}$ \\
\hline & Fisher ADF & $57.8277 * * *$ & $28.302 * * *$ & $28.6668^{* * *}$ & $15.885^{* *}$ \\
\hline & Fisher PP & $18.2084 * *$ & 0.0104 & $32.6859 * * *$ & 6.25149 \\
\hline \multirow[t]{3}{*}{$\operatorname{lnUR}$} & IPS & 0.6146 & 0.2320 & $-6.6725 * * *$ & $-5.4588 * * *$ \\
\hline & Fisher ADF & 4.3854 & 12.038 & $52.8569 * * *$ & $39.2314 * * *$ \\
\hline & Fisher PP & 5.1842 & 2.8842 & $53.9542 * * *$ & $39.4803 * * *$ \\
\hline
\end{tabular}

Note: $* * *$, and $* * *$ denote significance at the $1 \%, 5 \%$, and $10 \%$ levels, respectively, to test the null hypothesis of the existence of a unit root 
Table 5 Cointegration test results

\begin{tabular}{lllll}
\hline \multirow{2}{*}{ Test statistics } & \multicolumn{2}{l}{ Pedroni test } & & Westerlund test \\
\cline { 2 - 4 } & $\begin{array}{l}\text { Modified Phillips- } \\
\text { Perron } t\end{array}$ & Phillips-Perron $t$ & $\begin{array}{l}\text { Augmented Dickey- } \\
\text { Fuller } t\end{array}$ & $\begin{array}{l}\text { Variance ratio } \\
\text { Global }\end{array}$ \\
Africa & $5.6157^{* * *}$ & $-8.9511^{* * *}$ & $-12.1533^{* * * *}$ & $-5.6800^{* * *}$ \\
America & $1.8114^{* *}$ & $-1.7732^{* *}$ & -0.4193 & -1.0543 \\
Asia-Pacific & $4.0594^{* * *}$ & $-2.0261^{* *}$ & $-5.8393^{* * *}$ & $-2.0813^{* * *}$ \\
Europe & $4.5465^{* * *}$ & $-5.7062^{* * *}$ & $-8.1834^{* * *}$ & $-2.7792^{* *}$ \\
Middle East & $5.1589^{* * *}$ & $-11.2756^{* * *}$ & $-18.0941^{* * *}$ & $-4.0191^{* * *}$ \\
\hline
\end{tabular}

Note: $* * *$, and $* * *$ denote significance at the $1 \%, 5 \%$, and $10 \%$ levels, the null hypothesis of Pedroni test is no cointegration correlation, the null hypothesis of Westerlund test is no cointegration autocorrelation

\section{Panel unit root test and panel cointegration test}

In order to test the stability of the panel data and to test whether it can be modeled as a steady panel, this paper performs a unit root test on the panel data. We use unbalanced panels containing missing values in some years, and the tests with hidden assumptions of strongly balanced panels are not suitable for the data in this paper. Taking into account the data characteristics, the limitations of the unbalanced panels, and the characteristics of each sub-panel, we use the CIPS second-generation panel unit root test for the global, American, Asia-Pacific, and European panels and the first-generation panel unit root test (IPS, Fisher ADF, Fisher PP) for the Middle East and African panels. The specific results are shown in Table 3 and Table 4, respectively. The unit root test indicates that in all panels, the null hypothesis of the existence of unit root cannot be rejected for most of the data without any treatment. With the first-order difference treatment, almost all variables significantly reject the null hypothesis of the existence of unit root, and all series are first-order single integer series. It is reasonable to conduct cointegration tests and further study (Chishti et al. 2021a, b; Zhao et al. 2021).

On this basis, we perform cointegration tests, and Table 5 gives the results of Pedroni and Westerlund test, both with the null hypothesis that there is no cointegration relationship between the variables. The results of the tests indicate that the long-run cointegration relationship between $\mathrm{CO}_{2}$ emissions and its potential drivers is significantly supported in both the global panel and the regional panels, thus allowing us to further investigate the impact of drivers on $\mathrm{CO}_{2}$ emissions.

\section{Estimated results}

Based on the implementation of the above tests, the longrun parameters are estimated for the global panel and for five different regional panels. The tests show data characteristics of cross-sectional correlation, autocorrelation, heteroscedasticity, and first-order single integer of the data. Taking these data characteristics into account, we use the PCSE method to estimate the long-run parameters of the variables, and the parameters are estimated using robust estimation methods with Driscoll-Kraay standard error adjustment, which effectively reduce or avoid the estimation bias arising from single estimation method. In addition, the Hausman test results indicate the existence of individual fixed effects and random effects are not suitable for the data in this paper. Since various estimation methods exist only for relative accuracy but not absolute accuracy, referring to other literature, the regression results of fixed effects model (FEM) are also presented in this paper, and these estimation results will be compared. The specific estimates are presented in Table 6, and Fig. 8 compares the estimated results of the coefficients of each variable under the global and five different regional panels.

From the above estimation results, it can be seen that for most of the variables in all panels, there is no significant difference in the estimation results of different estimation methods. Next, the global panel and different regional panels are divided into separate discussions.

\section{Estimation results for the global panel}

Table 6 presents the estimation results of different estimation methods for the global panel. The estimation results show that all estimation methods consider the coefficients of $\ln P$, lnGDP, lnEI, lnADR, and lnUR pass the significance test. The coefficients of population size, per capita GDP, and energy intensity are positive, which have a positive driving effect on $\mathrm{CO}_{2}$ emissions. The coefficients of ADR and UR are minus and have a negative driving effect on $\mathrm{CO}_{2}$ emissions. Different estimators have different views on the possible effect of PUP on $\mathrm{CO}_{2}$ emissions but generally agree that the effect of 
Table 6 Estimation results

\begin{tabular}{|c|c|c|c|c|c|c|}
\hline & $\ln \mathrm{P}$ & $\operatorname{lnGDP}$ & $\operatorname{lnEI}$ & $\operatorname{lnPUP}$ & $\ln \mathrm{ADR}$ & $\operatorname{lnUR}$ \\
\hline \multicolumn{7}{|l|}{ Global } \\
\hline FEM & $\begin{array}{l}.8702 * * * \\
(.0150)\end{array}$ & $\begin{array}{l}.9602 * * * \\
(.0107)\end{array}$ & $\begin{array}{l}1.0494 * * * \\
(.0099)\end{array}$ & $\begin{array}{l}-.0145 \\
(.0303)\end{array}$ & $\begin{array}{l}-.1302 * * * \\
(.0180)\end{array}$ & $\begin{array}{l}-.0207 * * * \\
(.0042)\end{array}$ \\
\hline PCSE & $\begin{array}{l}1.0355^{* * *} \\
(.0048)\end{array}$ & $\begin{array}{l}.9583 * * * \\
(.0155)\end{array}$ & $\begin{array}{l}1.0026 * * * \\
(.0127\end{array}$ & $\begin{array}{l}.0558 \\
(.0367)\end{array}$ & $\begin{array}{l}-.0758 * * \\
(.0267)\end{array}$ & $\begin{array}{l}-.0175^{* * *} \\
(.0045)\end{array}$ \\
\hline Driscoll-Kraay & $\begin{array}{l}.8702 * * * \\
(.0371)\end{array}$ & $\begin{array}{l}.9602 * * * \\
(.0243)\end{array}$ & $\begin{array}{l}1.0494 * * * \\
(.0298)\end{array}$ & $\begin{array}{l}-.0145 \\
(.0635)\end{array}$ & $\begin{array}{l}-.1303^{* *} \\
(.0613)\end{array}$ & $\begin{array}{l}-.0207 * * \\
(.0086)\end{array}$ \\
\hline \multicolumn{7}{|l|}{ Africa } \\
\hline FEM & $\begin{array}{l}.9154 * * * \\
(.0327)\end{array}$ & $\begin{array}{l}.9387 * * * \\
(.0244)\end{array}$ & $\begin{array}{l}.9491 * * * \\
(.0235)\end{array}$ & $\begin{array}{l}.0675 \\
(.0510)\end{array}$ & $\begin{array}{l}-.0658^{* *} \\
(.0272)\end{array}$ & $\begin{array}{l}-.0229 * * \\
(.0105)\end{array}$ \\
\hline PCSE & $\begin{array}{l}1.6899 * * * \\
(.0670)\end{array}$ & $\begin{array}{l}.8221 * * * \\
(.0292)\end{array}$ & $\begin{array}{l}1.1213^{* * *} \\
(.0314)\end{array}$ & $\begin{array}{l}-1.366^{* * *} \\
(.1125)\end{array}$ & $\begin{array}{l}-.3536 * * * \\
(.0640)\end{array}$ & $\begin{array}{l}-.0351^{* *} \\
(.0165)\end{array}$ \\
\hline Driscoll-Kraay & $\begin{array}{l}.9154 * * * \\
(.0523)\end{array}$ & $\begin{array}{l}.9387 * * * \\
(.0247)\end{array}$ & $\begin{array}{l}.9491 * * * \\
(.0224)\end{array}$ & $\begin{array}{l}.0675 \\
(.0734)\end{array}$ & $\begin{array}{l}-.0658^{*} \\
(.2001)\end{array}$ & $\begin{array}{l}-.0229 * \\
(.0095)\end{array}$ \\
\hline \multicolumn{7}{|l|}{ America } \\
\hline FEM & $\begin{array}{l}.8809 * * * \\
(.0916)\end{array}$ & $\begin{array}{l}.9631 * * * \\
(.0370)\end{array}$ & $\begin{array}{l}1.0053^{* * *} \\
(.0489)\end{array}$ & $\begin{array}{l}.1250 \\
(.2804)\end{array}$ & $\begin{array}{l}-.0163 \\
(.0881)\end{array}$ & $\begin{array}{l}-.0392 * * \\
(.0133)\end{array}$ \\
\hline PCSE & $\begin{array}{l}.9595 * * * \\
(.0208)\end{array}$ & $\begin{array}{l}1.1431 \text { *** } \\
(.0402)\end{array}$ & $\begin{array}{l}.7445 * * * \\
(.0386)\end{array}$ & $\begin{array}{l}.0971 \\
(.1843)\end{array}$ & $\begin{array}{l}.4977 * * * \\
(.0789)\end{array}$ & $\begin{array}{l}-.0221 \\
(.0134)\end{array}$ \\
\hline Driscoll-Kraay & $\begin{array}{l}.9677 * * * \\
(.0036)\end{array}$ & $\begin{array}{l}1.3079 * * * \\
(.0384)\end{array}$ & $\begin{array}{l}.6182 * * * \\
(.0307)\end{array}$ & $\begin{array}{l}-.2003 * \\
(.0658)\end{array}$ & $\begin{array}{l}.6837 * * * \\
(.0682)\end{array}$ & $\begin{array}{l}-.0531 * * * \\
(.0111)\end{array}$ \\
\hline \multicolumn{7}{|l|}{ Asia-Pacific } \\
\hline FEM & $\begin{array}{l}1.0447 * * * \\
(.0310)\end{array}$ & $\begin{array}{l}.9898 * * * \\
(.0158)\end{array}$ & $\begin{array}{l}1.0463^{* * *} \\
(.0137)\end{array}$ & $\begin{array}{l}-.0080 \\
(.0355)\end{array}$ & $\begin{array}{l}-.0382 \\
(.0288)\end{array}$ & $\begin{array}{l}-.0088 \\
(.0059)\end{array}$ \\
\hline PCSE & $\begin{array}{l}1.0329 * * * \\
(.0083)\end{array}$ & $\begin{array}{l}.9873 * * * \\
(.0281)\end{array}$ & $\begin{array}{l}1.0377 * * * \\
(.0148)\end{array}$ & $\begin{array}{l}.0782 \\
(.0786)\end{array}$ & $\begin{array}{l}-.1885^{* *} \\
(.0608)\end{array}$ & $\begin{array}{l}-.0064 \\
(.0062)\end{array}$ \\
\hline Driscoll-Kraay & $\begin{array}{l}1.0395 * * * \\
(.0048)\end{array}$ & $\begin{array}{l}.9522 * * * \\
(.0405)\end{array}$ & $\begin{array}{l}1.0514 * * * \\
(.0058)\end{array}$ & $\begin{array}{l}.1112 * \\
(.0564)\end{array}$ & $\begin{array}{l}-.4022 * * * \\
(.0796)\end{array}$ & $\begin{array}{l}.0051 \\
(.0229)\end{array}$ \\
\hline \multicolumn{7}{|l|}{ Europe } \\
\hline FEM & $\begin{array}{l}.5577 * * * \\
(.0393)\end{array}$ & $\begin{array}{l}.8280 * * * \\
(.0256)\end{array}$ & $\begin{array}{l}1.0167 * * * \\
(.0214)\end{array}$ & $\begin{array}{l}.0564 \\
(.0826)\end{array}$ & $\begin{array}{l}-.3489 * * * \\
(.0389)\end{array}$ & $\begin{array}{l}-.0438^{* * *} \\
(.0077)\end{array}$ \\
\hline PCSE & $\begin{array}{l}1.0179 * * * \\
(.0094)\end{array}$ & $\begin{array}{l}.8013 * * * \\
(.0342)\end{array}$ & $\begin{array}{l}.8851 * * * \\
(.0291)\end{array}$ & $\begin{array}{l}.0959 \\
(.0987)\end{array}$ & $\begin{array}{l}-.4087 * * * \\
(.1198)\end{array}$ & $\begin{array}{l}-.0386^{* * * *} \\
(.0116)\end{array}$ \\
\hline Driscoll-Kraay & $\begin{array}{l}1.0106 \text { *** } \\
(.0031)\end{array}$ & $\begin{array}{l}.6045^{* * * *} \\
(.0343)\end{array}$ & $\begin{array}{l}.5843 * * * \\
(.0300)\end{array}$ & $\begin{array}{l}.2965 * * * \\
(.0575)\end{array}$ & $\begin{array}{l}-1.1567 * * * \\
(.1730)\end{array}$ & $\begin{array}{l}-.0012 \\
(.0232)\end{array}$ \\
\hline \multicolumn{7}{|l|}{ Middle East } \\
\hline FEM & $\begin{array}{l}.9827 * * * \\
(.0146)\end{array}$ & $\begin{array}{l}.9910 * * * \\
(.0148)\end{array}$ & $\begin{array}{l}.9548 * * * \\
(.0140)\end{array}$ & $\begin{array}{l}-.5572 * * * \\
(.0920)\end{array}$ & $\begin{array}{l}-.0153 \\
(.0241)\end{array}$ & $\begin{array}{l}.0004 \\
(.0060)\end{array}$ \\
\hline PCSE & $\begin{array}{l}.9944 * * * \\
(.0107)\end{array}$ & $\begin{array}{l}.9894 * * * \\
(.0141)\end{array}$ & $\begin{array}{l}.9817 * * * \\
(.0148)\end{array}$ & $\begin{array}{l}-.1577 \\
(.1037)\end{array}$ & $\begin{array}{l}.0564 * * \\
(.0276)\end{array}$ & $\begin{array}{l}.0048 \\
(.0060)\end{array}$ \\
\hline Driscoll-Kraay & $\begin{array}{l}.9541 * * * \\
(.0039)\end{array}$ & $\begin{array}{l}.9344 * * * \\
(.0173)\end{array}$ & $\begin{array}{l}.8436 * * * \\
(.0551)\end{array}$ & $\begin{array}{l}.1047 \\
(.0571)\end{array}$ & $\begin{array}{l}-.0205 \\
(.0327)\end{array}$ & $\begin{array}{l}.0632 * * * \\
(.0104)\end{array}$ \\
\hline
\end{tabular}

Note: $* * *$, and $* * *$ indicate significance at the $1 \%, 5 \%$, and $10 \%$ levels, respectively

urban population share on $\mathrm{CO}_{2}$ emissions is insignificant or only weakly significant. Focusing on the key variables of this paper, PCSE estimates suggest that each $1 \%$ increase in the ADR and UR will result in a $0.0758 \%$ and $0.0175 \%$ reduction in $\mathrm{CO}_{2}$ emissions, and the $\mathrm{D}-\mathrm{K}$ estimation suggests that this rate is $0.1303 \%$ and $0.0207 \%$. Combining FEM, these estimates are considered reasonable. The above estimation results confirm hypothesis 1 and hypothesis 3 and are consistent with the results obtained by Wang and Li (2021).

\section{Estimation results of different regional panels}

The estimation results for the regional panels are also presented in Table 6. In each region, almost all estimation methods affirm the positive driving effects of population size, GDP per capita, and energy intensity on $\mathrm{CO}_{2}$ emissions. Further, we discuss the specifics of each region.

In the African panel, all estimators conclude that nurturing pressure leads to a significant reduction in $\mathrm{CO}_{2}$ emissions in the long run. The PCSE estimates suggest that a $1 \%$ 

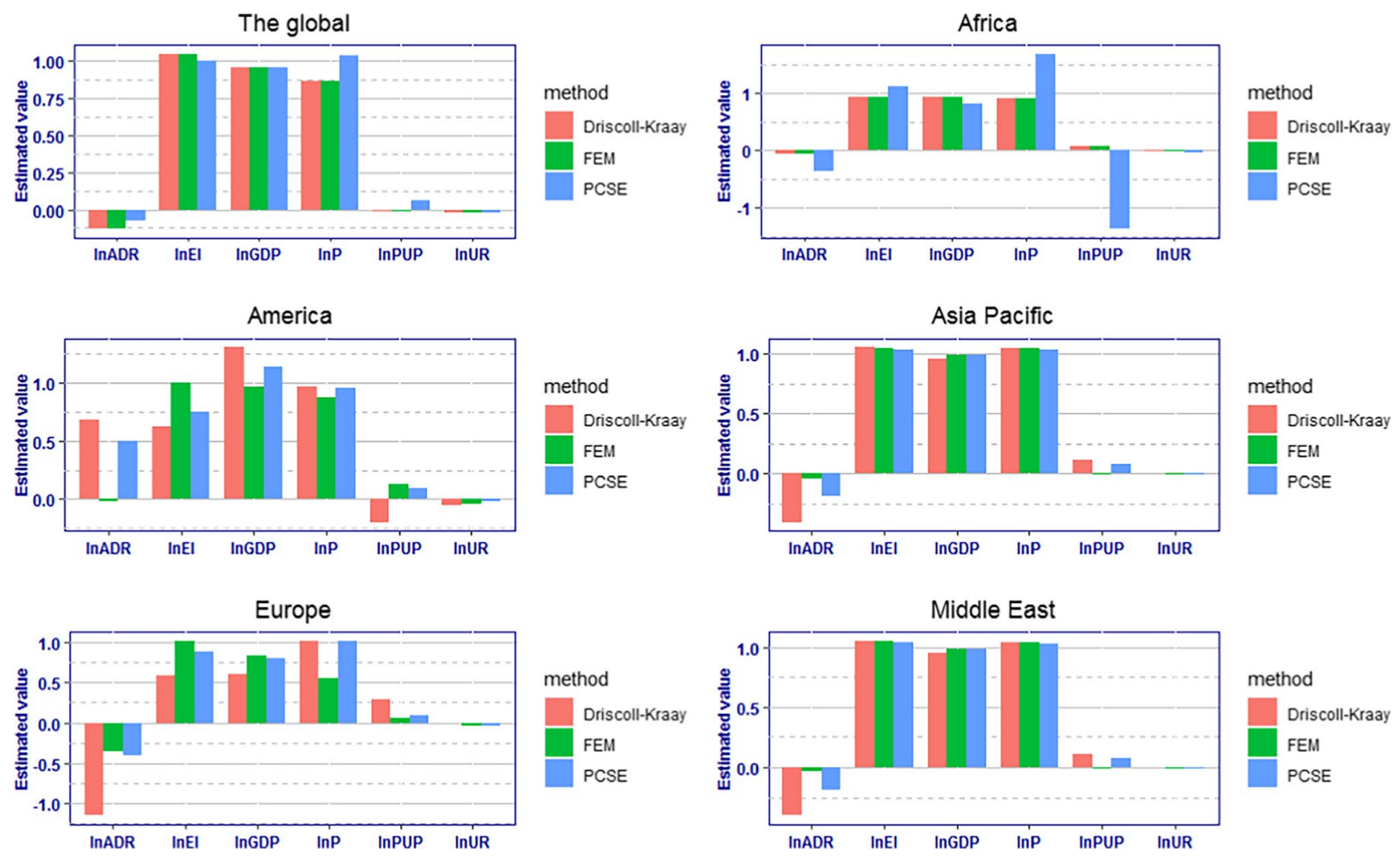

Fig. 8 Estimated results of global panel and different regional panel coefficients

increase in ADR leads to a $0.3536 \%$ decrease in $\mathrm{CO}_{2}$ emissions. While the FEM and Driscoll-Kraay standard erroradjusted estimates have slightly smaller decision values for this coefficient, the evidence is sufficient to show a negative effect of nurturing pressure on $\mathrm{CO}_{2}$ emissions in Africa. The estimation results likewise indicate a negative effect of unemployment on $\mathrm{CO}_{2}$ emissions in Africa. According to the PCSE estimation results, a $1 \%$ increase in UR decreases $\mathrm{CO}_{2}$ emissions by $0.0351 \%$ in the long run, and other estimators show similar results. Although the magnitude of the effect of unemployment on $\mathrm{CO}_{2}$ emissions appears to be less than that of the traditional drivers of carbon emissions that have been receiving much attention, the excellent significance implies that it is worthy of being drawn to attention.

However, the situation is different in the Americas' panel, where our results show that nurturing pressure has a positive effect on $\mathrm{CO}_{2}$ emissions. According to PCSE estimates, a $1 \%$ increase in $\mathrm{ADR}$ increases $\mathrm{CO}_{2}$ emissions by $0.4977 \%$, and Driscoll-Kraay standard error-adjusted estimates put this increase at $0.6837 \%$, and both have strong significance. All three estimators conclude that unemployment has a negative effect on $\mathrm{CO}_{2}$ emissions. According to the PCSE estimates, a $1 \%$ increase in unemployment decreases $\mathrm{CO}_{2}$ emissions by $0.0221 \%$. The impact of nurturing pressure on carbon emissions in the Asia-Pacific region is less significant than that in the Americas. As with the Africa panel, nurturing pressure drives $\mathrm{CO}_{2}$ emissions negatively, and the PCSE estimates that a $1 \%$ increase in ADR would reduce $\mathrm{CO}_{2}$ emissions by $0.1885 \%$. A $1 \%$ increase in unemployment would reduce $\mathrm{CO}_{2}$ emissions by about $0.0064 \%$, but the effect of unemployment on $\mathrm{CO}_{2}$ emissions in the Asia-Pacific region is not statistically significant.

It is worth noting that the effects of nurturing pressure and unemployment on $\mathrm{CO}_{2}$ emissions in the European region are highly significant. According to the FEM, PCSE, and Driscoll-Kraay standard error-adjusted estimates, a $1 \%$ increase in ADR leads to a $0.3489 \%, 0.4087 \%$, and $1.1567 \%$ decrease in carbon emissions, and a $1 \%$ increase in unemployment would result in a $0.0438 \%, 0.0386 \%$, and $0.0012 \%$ decrease in carbon emissions. It seems that carbon emission reduction in the European region should be more concerned about the potential impact of nurturing pressure and unemployment than in other regions and that population and employment policies should be proposed not only for economic development considerations alone, but also for their possible impact on the environment.

There are some arguments among different estimators about the driving effects of nurturing pressure and 
unemployment on $\mathrm{CO}_{2}$ emissions in the Middle East. The PCSE estimates suggest that a $1 \%$ increase in ADR increases $\mathrm{CO}_{2}$ emissions by $0.0564 \%$, but the Driscoll-Kraay standard error estimates suggest that this effect is negative. The PCSE estimates also suggest that a $1 \%$ increase in UR increases $\mathrm{CO}_{2}$ emissions by $0.0048 \%$. Considering all estimation methods together, the effects of nurturing pressure and unemployment on $\mathrm{CO}_{2}$ emissions are not statistically significant, and more consideration should be given to traditional carbon emission drivers for carbon reduction in Middle Eastern countries compared to other regions. The above analysis shows that the effects of nurturing pressure and unemployment on $\mathrm{CO}_{2}$ emissions vary across different regions of the globe, supporting hypothesis 2 and hypothesis 4 .

\section{Conclusions and policy implications}

Based on a global perspective, this paper collects panel data for 77 countries and regions from 1991 to 2020 and empirically explores the driving effects of two demographic factors, nurturing pressure and unemployment, on carbon emissions globally and in different regions based on a modified STIRPAT model. By testing the panel data, different estimation methods are used to estimate and compare the long-run parameters of the independent variables, and targeted suggestions are made for the different influential roles exhibited by ADR and UR in different regions, respectively.

The specific conclusions of this paper are as follows.

(1) Global $\mathrm{CO}_{2}$ emissions show an overall steady upward trend during 1991-2020 and have reached 31,983.6 millions of tons by 2020 , with a growth rate of $49.86 \%$ over 30 years and an average annual growth rate of $1.4 \%$ from 1991 to 2019. In all regions, $\mathrm{CO}_{2}$ emissions are relatively high in Europe, Asia-Pacific, and the Americas. There is still a further upward trend of global $\mathrm{CO}_{2}$ emissions in the future.

(2) The global ADR shows an obvious U-shaped feature, and in 2010, it achieved an inflection point from decreasing to increasing, among which the ADR in Africa and the Americas as a whole are slightly higher than those in other regions, and the ADR varies greatly among countries in the Middle East. Unemployment rates are generally on a declining trend, with Asia-Pacific having the lowest UR and Africa having the highest.

(3) Globally, nurturing pressure and unemployment have a negative driving effect on $\mathrm{CO}_{2}$ emissions. Although the effects are less significant than traditional carbon emission influences such as population size and GDP per capita, they are statistically significant. Continent-specific, both nurturing pressure and unemployment have statistically significant effects on $\mathrm{CO}_{2}$ emissions in most regions, but the directionality of this effect is not consistent, and the magnitude of the effect varies. Although there are differences in the estimates considering different data characteristics, for countries and regions in Africa, the Americas, Asia-Pacific, Europe, and the Middle East, it is generally agreed that a positive change in the ADR will have a negative, positive, negative, negative, and positive impact on $\mathrm{CO}_{2}$ emissions, and a positive change in the UR will have a negative, negative, negative, negative, and positive impact on $\mathrm{CO}_{2}$ emissions.

Following the conclusions discussed above, some policy recommendations emerge from the findings. First, our study confirms that Europe, Asia-Pacific, and the Americas are regions with relatively high $\mathrm{CO}_{2}$ emissions. In the future, when global $\mathrm{CO}_{2}$ emissions are still on an unstoppable upward trend, carbon emission reduction in these key regions should receive more attention and focus. The global green and low-carbon development is not just a matter for a certain country or region, and the related international cooperation and communication should be further developed.

Second, our study shows that nurturing pressures and unemployment have a negative impact on $\mathrm{CO}_{2}$ emissions at the global and some regional levels. It is worth noting, however, that we cannot use a precipitous increase in nurturing pressure or unemployment to achieve carbon reduction targets, because pursuing carbon reduction targets without considering other factors will have serious consequences, both in terms of national development and people's livelihoods. Clearly, there is a trade-off between economic development, people's quality of life, and carbon emission reduction. Especially considering the potentially significant negative impact of unemployment on economic development, an increase in unemployment will limit sustainable economic and social development and even trigger serious political and social crises. Especially for some developing countries, the formulation of relevant carbon emission reduction policies must take into account the development stage and level of development the country is at. In some countries with low birth rates, population policies can be coordinated with environmental policies, and the relevant policy-making departments should not be completely separated from each other.

Third, a comparative analysis at the regional level shows that different countries and regions by geography exhibit significant heterogeneity. For countries in the Americas and the Middle East, where ADR has a positive impact, population policies that help reduce the pressure to raise children, such as reasonable incentives for childbearing, may have a positive impact in the future in order to promote $\mathrm{CO}_{2}$ reduction. For countries and regions in Africa, 
Asia-Pacific, and Europe, where ADR has a negative impact, although the policy direction of increasing ADR is not realistic and may cause greater dependency pressure, focusing on and controlling healthy demographic changes will still have a positive impact on carbon emission reduction. For countries in the Middle East where the UR has a positive impact, policies to reduce the unemployment rate are not only meaningful for the improvement of national livelihoods, but also bring positive effects on environmental impacts in the future. At the same time, the government should pay attention to guiding non-workers' lifestyles and consumption patterns in a healthy way. For countries and regions in the Americas, Africa, Asia-Pacific, and Europe, where UR has a negative impact, promoting the rational adjustment and transformation of industrial structure and upgrading and paying more attention to the cultivation and development of low-carbon industries in the future will be beneficial to long-term $\mathrm{CO}_{2}$ emission reduction. It is important to note that there is no policy direction that applies to all countries and regions.

Author contribution Yu-Qi Liu, conceptualization, methodology, formal analysis, investigation, writing - original draft, and writing - review and editing; Chao Feng, conceptualization, methodology, formal analysis, investigation, writing — original draft, and writing - review and editing.

Funding We gratefully acknowledge financial support from the National Natural Science Foundation of China (No. 72003017), the National Social Science Foundation of China (No. 19ZDA082), and the Fundamental Research Funds for the Central Universities (No. 2021CDJSKCG19).

Availability of data and materials The datasets used in this study are available from the corresponding author on reasonable request.

\section{Declarations}

Ethics approval Not applicable.

Consent to participate We confirm that the manuscript has been read and approved by all named authors and that there are no other persons who satisfied the criteria for authorship but are not listed. We further confirm that the order of authors listed in the manuscript has been approved by all of us.

Consent for publication The authors agree to publish this article in the Environmental Science and Pollution Research.

Competing interests The authors declare no competing interests.

\section{References}

Adesina KS, Mwamba JWM (2019) Does economic freedom matter for $\mathrm{CO}_{2}$ emissions? Lessons from Africa. The Journal of Developing Areas 53(3):155-167
Anser MK, Syed QR, Apergis N (2021) Does geopolitical risk escalate $\mathrm{CO}_{2}$ emissions? Evidence from the BRICS countries. Environ Sci Pollut Res 28(12):1-11

Berg J, Hilal A, El S, Horne R. (2021) World employment and social

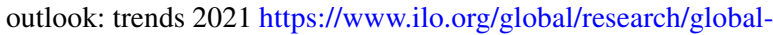
reports/weso/trends2021/WCMS_795453/lang--en/index.htm

Beck N, Katz JN (1995) What to do (and not to do) with time-series cross-section data. Am Polit Sci Rev 89(3):634-647

BP. (2021) BP Statistical Review of World Energy 2021. https://www. bp.com/content/dam/bp/business-sites/en/global/corporate/pdfs/ energy-economics/statistical-review/bp-stats-review-2021-fullreport.pdf

Breusch TS, Pagan AR (1980) The Lagrange multiplier test and its applications to model specification in econometrics. Rev Econ Stud 47(1):239-253

Chen MJ, Kumar GS, Malin M, Wen SJ, (2020) Effects of technological changes on China's carbon emissions. Technological Forecasting and Social Change 153119938. https://doi.org/10.1016/j.techf ore.2020.119938

Chen F, Jiang G, Kitila GM (2021) Trade openness and $\mathrm{CO}_{2}$ emissions: the heterogeneous and mediating effects for the belt and road countries. Sustainability 13(4):1958

Chong CH, Tan WX, Ting ZJ, Liu P, Ma L, Li Z, Ni W (2019) The driving factors of energy-related $\mathrm{CO}_{2}$ emission growth in Malaysia: the LMDI decomposition method based on energy allocation analysis. Renew Sustain Energy Rev 115:109356

Chishti MZ, Ullah S, Ozturk I, Usman A (2020) Examining the asymmetric effects of globalization and tourism on pollution emissions in South Asia. Environ Sci Pollut Res 27(22). https://doi.org/10. 1007/s11356-020-09057-9

Chishti MZ, Rehman A, Murshed M (2021a) An estimation of the macroeconomic determinants of income poverty in Pakistan? Evidence from a non-linear ARDL approach. Journal of Public Affairs e2719. https://doi.org/10.1002/pa.2719

Chishti MZ, Ahmad M, Rehman A, Khan MK (2021b) Mitigations pathways towards sustainable development: assessing the influence of fiscal and monetary policies on carbon emissions in BRICS economies. Journal of Cleaner Production 292:126035

Chishti MZ, Sinha A (2022) Do the shocks in technological and financial innovation influence the environmental quality? Evidence from BRICS economies. Technology in Society 68:101828

Chontanawat $\mathbf{J}$ (2018) Decomposition analysis of $\mathrm{CO}_{2}$ emission in ASEAN: an extended IPAT model. Energy Procedia 153:186-190

Commoner B (1990) Making peace with the planet. Pantheon Books

Cranston GR, Hammond GP (2010) Egalite, fraternite, sustainabilite: evaluating the significance of regional affluence and population growth on carbon emissions. International Journal of Global Warming 2(3):189-210

Dietz T, Rosa EA (1994) Rethinking the environmental impacts of population, affluence and technology. Hum Ecol Rev 1(2):277-300

Dong K, Dong X, Dong C (2019) Determinants of the global and regional $\mathrm{CO}_{2}$ emissions: what causes what and where? Appl Econ 51(46):5031-5044

Dong Y, Ishikawa M, Liu X, Wang C (2010) An analysis of the driving forces of $\mathrm{CO}_{2}$ emissions embodied in Japan-China trade. Energy Policy 38(11):6784-6792

Dou Y, Zhao J, Malik MN, Dong K (2021) Assessing the impact of trade openness on $\mathrm{CO}_{2}$ emissions: evidence from China-JapanROK FTA countries. J Environ Manag 296:113241

Driscoll JC, Kraay AC (1998) Consistent covariance matrix estimation with spatially dependent panel data. Rev Econ Stat 80(4):549-560

Holdren JP, Ehrlich PR (1972) One-dimensional ecology revisited a rejoinder. Bulletin of the Atomic Scientists 28(6):42-45

Guo S, He P, Bayaraa M, Li J (2020) Greenhouse gas emissions embodied in the Mongolian economy and their driving forces. Sci Total Environ 714:136378 
Haug AA, Ucal M (2019) The role of trade and FDI for $\mathrm{CO}_{2}$ emissions in Turkey: nonlinear relationships. Energy Economics 81:297-307

Jayantha WM, Qian QK, Yi CO (2018) Applicability of 'aging in place' in redeveloped public rental housing estates in Hong Kong. Cities 83:140-151

Jiang M, An H, Gao X, Jia N, Liu S, Zheng H (2021) Structural decomposition analysis of global carbon emissions: the contributions of domestic and international input changes. J Environ Manag 294:112942

Kao C (1999) Spurious regression and residual-based tests for cointegration in panel data. Journal of Econometrics 90(1):1-44

Kapetanios G, Pesaran MH, Yamagata T (2011) Panels with nonstationary multifactor error structures. Journal of Econometrics 160(2):326-348

Kashem MA, Rahman MM (2020) Environmental Phillips curve: OECD and Asian NICs perspective. Environ Sci Pollut Res 27(1):31153-31170

Kim J, Lim H, Jo HH (2020) Do aging and low fertility reduce carbon emissions in Korea? Evidence from IPAT augmented EKC analysis. Int J Environ Res Public Health 17(8):2972

Li J, Chen Y, Li Z, Liu Z (2018) Quantitative analysis of the impact factors of conventional energy carbon emissions in Kazakhstan based on LMDI decomposition and STIRPAT model. J Geog Sci 28(7):1001-1019

Li J, Han X, Zhang X, Wang S (2019a) Spatiotemporal evolution of global population ageing from 1960 to 2017. BMC Public Health 19(1):1-15

Li Q, Wu S, Lei Y, Li S, Li L (2021) Evolutionary path and driving forces of inter-industry transfer of $\mathrm{CO}_{2}$ emissions in China: evidence from structural path and decomposition analysis. Sci Total Environ 765:142773

Li R, Li S (2021) Carbon emission post-coronavirus: continual decline or rebound? Struct Chang Econ Dyn 57:57-67

Li S, Deng H, Zhang K (2019b) The impact of economy on carbon emissions: an empirical study based on the synergistic effect of gender factors. Int J Environ Res Public Health 16(19):3723

Lin B, Long H (2016) Emissions reduction in China's chemical industry-based on LMDI. Renew Sustain Energy Rev 53:1348-1355

Liu X, Zhou D, Zhou P, Wang Q (2017) What drives $\mathrm{CO}_{2}$ emissions from China's civil aviation? An exploration using a new generalized PDA method. Transportation Research Part a: Policy and Practice 99:30-45

Lütkepohl H, Burda MM (1997) Modified Wald tests under nonregular conditions. Journal of Econometrics 78(2):315-332

Meng Z, Wang H, Wang B (2018) Empirical analysis of carbon emission accounting and influencing factors of energy consumption in China. Int J Environ Res Public Health 15(11):2467

Mensah CN, Long X, Boamah KB, Bediako IA, Dauda L, Salman $\mathrm{M}$ (2018) The effect of innovation on $\mathrm{CO}_{2}$ emissions of OCED countries from 1990 to 2014. Environ Sci Pollut Res 25(29):29678-29698

Pachauri RK, Allen MR, Barros VR, Broome J, Cramer W, Christ R, Dasgupta P (2014) Climate change 2014: synthesis report. Contribution of Working Groups I, II and III to the fifth assessment report of the Intergovernmental Panel on Climate Change. Ipcc https://epic.awi.de/id/eprint/37530/1/IPCC_AR5_SYR_Final.pdf

Palm FC, Smeekes S, Urbain JP (2011) Cross-sectional dependence robust block bootstrap panel unit root tests. Journal of Econometrics 163(1):85-104

Pan X, Li M, Wang M, Zong T, Song M (2020) The effects of a Smart Logistics policy on carbon emissions in China: A difference-indifferences analysis. Transportation Research Part E: Logistics and Transportation Review 137101939. https://doi.org/10.1016/j. tre.2020.101939

Pedroni P (2004) Panel cointegration: asymptotic and finite sample properties of pooled time series tests with an application to the PPP hypothesis. Economet Theor 20(3):597-625
Pesaran MH (2004) General diagnostic tests for cross section dependence in panels. Cambridge Working Papers in Economics 69(7): 1240

Pesaran MH (2007) A simple panel unit root test in the presence of cross-section dependence. J Appl Economet 22(2):265-312

Pesaran MH, Ullah A, Yamagata T (2008) A bias-adjusted LM test of error cross-section independence. Economet J 11(1):105-127

Rahman A, Ma H, Ahmad M, Ozturk I, Chishti MZ (2021) How do climatic change, cereal crops and livestock production interact with carbon emissions? Updated evidence from China. Environmental Science and Pollution Research 1-12. https://doi.org/10. 1007/s11356-021-12948-0

Timilsina GR, Shrestha A (2009) Transport sector $\mathrm{CO}_{2}$ emissions growth in Asia: underlying factors and policy options. Energy Policy 37(11):4523-4539

Tong X, Li X, Tong L, Jiang X (2018) Spatial spillover and the influencing factors relating to provincial carbon emissions in China based on the spatial panel data model. Sustainability 10(12):4739

Tong X, Tong L, Li X (2016) Empirical study on spatial spillover of provincial carbon emissions and influencing factors in China. Chinese Control and Decision Conference (CCDC), 1009-1013. https://doi.org/10.1109/CCDC.2016.7531131.

Ullah S, Majeed MT, Chishti MZ (2020) Examining the asymmetric effects of fiscal policy instruments on environmental quality in Asian economies. Environ Sci Pollut Res 27(30):38287-38299

Wang C (2011) Sources of energy productivity growth and its distribution dynamics in China. Resource and Energy Economics 33(1):279-292

Wang C, Wang F, Zhang X, Yang Y, Su Y, Ye Y, Zhang H (2017) Examining the driving factors of energy related carbon emissions using the extended STIRPAT model based on IPAT identity in Xinjiang. Renew Sustain Energy Rev 67:51-61

Wang Y, Duan F, Ma X, He L (2019) Carbon emissions efficiency in China: key facts from regional and industrial sector. J Clean Prod 206:850-869

Wang Q, Jiang X-t, Ge S, Jiang R, (2019) Is economic growth compatible with a reduction in $\mathrm{CO} 2$ emissions? Empirical analysis of the United States. Resources Conservation and Recycling 151104443. https://doi.org/10.1016/j.resconrec.2019.104443

Wang Q, Liu Y, Wang H, (2019) Determinants of net carbon emissions embodied in Sino-German trade. Journal of Cleaner Production 2351216-1231. https://doi.org/10.1016/j.jclepro.2019.07.011

Wang Z, Jiang Q, Dong K, Mubarik MS, Dong X (2020) Decomposition of the US $\mathrm{CO}_{2}$ emissions and its mitigation potential: an aggregate and sectoral analysis. Energy Policy 147:111925

Wang S, Tang Yun, Du Z, Song M, (2020) Export trade embodied carbon emissions and environmental pollution: An empirical analysis of China's high- and new-technology industries. Journal of Environmental Management 276111371. https://doi.org/10. 1016/j.jenvman.2020.111371

Wang Q, Li L (2021) The effects of population aging, life expectancy, unemployment rate, population density, per capita GDP, urbanization on per capita carbon emissions. Sustainable Production and Consumption 28:760-774

Wang Q, Wang Li (2021) The nonlinear effects of population aging industrial structure and urbanization on carbon emissions: A panel threshold regression analysis of 137 countries. Journal of Cleaner Production 287125381. https://doi.org/10.1016/j.jclepro. 2020.125381

Weimin Z, Chishti MZ, Rehman A, Ahmad M (2021) A pathway toward future sustainability: assessing the influence of innovation shocks on $\mathrm{CO} 2$ emissions in developing economies. Environment, Development and Sustainability 1-24. https://doi.org/10. 1007/s10668-021-01634-3

Wen L, Shao H (2019) Analysis of influencing factors of the carbon dioxide emissions in China's commercial department based on 
the STIRPAT model and ridge regression. Environ Sci Pollut Res 26(26):27138-27147

Wen L, Zhang Z (2020) Probing energy-related $\mathrm{CO}_{2}$ emissions in the Beijing-Tianjin-Hebei region based on ridge regression considering population factors. Pol J Environ Stud 29(3):2413-2427

Westerlund J (2005) New simple tests for panel cointegration. Economet Rev 24(3):297-316

Westerlund J, Edgerton DL (2007) A panel bootstrap cointegration test. Econ Lett 97(3):185-190

Wooldridge JM (2010) Econometric analysis of cross section and panel data. MIT press. http://213.55.90.4/admin/home/Dmu\% 20Academic\%20Resource/Postgraduate\%20Studies/Accounting\% 20 and $\% 20$ finance/WOOLDRIDGE\% 20ECONOMETRIC $\%$ 20ANALYSIS.PDF

Xu L, Du H, Zhang X (2021) Driving forces of carbon dioxide emissions in China's cities: an empirical analysis based on the geodetector method. J Clean Prod 287:125169

Yang T, Wang Q (2020) The nonlinear effect of population aging on carbon emission-empirical analysis of ten selected provinces in China. Sci Total Environ 740:140057

Yang S, Zhao D, Wu Y, Fan J (2013) Regional variation in carbon emissions and its driving forces in China: an index decomposition analysis. Energy \& Environment 24(7-8):1249-1270

Yang J, Hao Y, Feng C (2021) A race between economic growth and carbon emissions: What play important roles towards global lowcarbon development?. Energy Economics 100105327. https://doi. org/10.1016/j.eneco.2021.105327

York R, Rosa EA, Dietz T (2003) STIRPAT, IPAT and ImPACT: analytic tools for unpacking the driving forces of environmental impacts. Ecol Econ 46(3):351-365
Zhang C, Tan Z (2016) The relationships between population factors and China's carbon emissions: does population aging matter? Renew Sustain Energy Rev 65:1018-1025

Zhang HW, Zhang SY, Shi LY (2013) The comparative study of China's low carbon pilot provinces $\mathrm{CO}_{2}$ emission characteristics and influence factors. Advanced Materials Research 734:1948-1955

Zhao J, Shahbaz M, Dong X, Dong K (2021) How does financial risk affect global $\mathrm{CO}_{2}$ emissions? The role of technological innovation. Technological Forecasting and Social Change 168:120751

Zhao QZ, Yan QY (2013) Driving factors analysis of carbon dioxide emissions in China based on STIRPAT model. Adv Mater Res 734:1910-1914

Zhao T, Gou X (2013) Analyzing the driving effect of influence factors on $\mathrm{CO}_{2}$ emissions using the STIRPAT model in Tianjin of China. Adv Mater Res 734:1896-1900

Zheng H, Song M, Shen Z (2021) The evolution of renewable energy and its impact on carbon reduction in China. Energy 237121639. https://doi.org/10.1016/j.energy.2021.121639

Zhou Y, Fu J, Kong Y, Wu R (2018) How foreign direct investment influences carbon emissions, based on the empirical analysis of Chinese urban data. Sustainability 10(7):2163

Zhu C, Du W (2019) A research on driving factors of carbon emissions of road transportation industry in six Asia-Pacific countries based on the LMDI decomposition method. Energies 12(21):4152

Publisher's Note Springer Nature remains neutral with regard to jurisdictional claims in published maps and institutional affiliations. 